\title{
Refinements to SSiB with an emphasis on snow-physics: Evaluation and validation using GSWP and Valdai data
}

David M. Mocko* and Y.C. Sud

Laboratory for Atmospheres

NASA Goddard Space Flight Center

Greenbelt, Maryland

Corresponding author address:

David M. Mocko

Code 913, Climate and Radiation Branch

Laboratory for Atmospheres

NASA Goddard Space Flight Center

Greenbelt, MD, USA 20771

E-mail: mocko@climate.gsfc.nasa.gov

URL: http://climate.gsfc.nasa.gov/ ${ }^{\sim}$ mocko/

May 12,2000

*Additional Affiliation: General Sciences Corporation, Beltsville MD 


\begin{abstract}
Refinements to the snow-physics scheme of SSiB are described and evaluated. The upgrades include a partial re-design of the conceptual architecture to better simulate the diurnal temperature of the snow surface. For a deep snowpack, there are two separate prognostic temperature snow layers - the top layer responds to diurnal fluctuations in the surface forcing, while the deep layer exhibits a slowly varying response. In addition, the use of a very deep soil temperature and a treatment of snow aging with its influence on snow density is parameterized and evaluated. The upgraded snow scheme produces better timing of snow melt in GSWP-style simulations using ISLSCP Initiative I data for 1987-1988 in the Russian Wheat Belt region.

To simulate more realistic runoff in regions with high orographic variability, additional improvements are made to SSiB's soil hydrology. These improvements include an orographybased surface runoff scheme as well as interaction with a water table below SSiB's three soil layers. The addition of these parameterizations further help to simulate more realistic runoff and accompanying prognostic soil moisture fields in the GSWP-style simulations.

In intercomparisons of the performance of the new snow-physics SSiB with its earlier versions using an 18-year single-site dataset from Valdai, Russia, the version of SSiB described in this paper again produces the earliest onset of snow melt. Soil moisture and deep soil temperatures also compare favorably with observations.
\end{abstract}




\section{Introduction and Motivation}

The Simplified Simple Biosphere Model (SSiB) (Xue et al., 1991) is a biophysical model of land-atmosphere interactions, which was designed to simulate land-surface processes in numerical models realistically. The interactions are calculated from the fundamental governing equations (Sellers et al., 1986) and provide fluxes of radiation absorption, reflection, and emission together with momentum, sensible, and latent heat to general circulation models (GCMs) and regional models. SSiB has been calibrated for a number of biomes using observational data taken from several regions of the world. In these calibrations and/or evaluations, atmospheric data serve as external forcing, while the model simulates soil/vegetation temperature(s), soil moisture(s), and surface fluxes that are compared with observations. Thus far, validation datasets include the Russian soil moisture data (Robock et al., 1995; Schlosser et al., 1997; Xue et al., 1997), the HAPEX-Mobilhy data from France (Xue, Zeng, and Schlosser, 1996), the Cabauw data from Netherlands (Chen et al., 1997), the Anglo-Brazilian Amazonian Climate Observation Study (ABRACOS) data (Xue et al., 1996), the Sahelian Energy Balance Experiment (SEBEX), and HAPEX-Sahel field measurement data from Niger (Xue, 1997). Some evaluations were part of the Project for Intercomparison of Land-Surface Parameterization Scheme (PILPS, Henderson-Sellers et al., 1993), while others were part of the Global Soil Wetness Project (GSWP, Dirmeyer et al., 1999) which used ISLSCP Initiative I data (Meeson et al., 1995; Sellers et al., 1995). SSiB was included in an NCEP land-surface model intercomparison (Chen et al., 1996) using the First ISLSCP Field Experiment (FIFE) data. These evaluations have not only helped to improve $\mathrm{SSiB}$, but also to understand the mechanisms of land-surface processes in different 
parts of the world experiencing different climatic conditions, vegetation, and soils. In this way, the ongoing research, development, and evaluation of SSiB has paved the way for more complex interaction studies in a model coupled to a GCM or regional model. $\mathrm{SSiB}$ is used within the Goddard Earth Observing System (GEOS) II GCM (Takacs et al., 1994) as well as the Eta model used by NCEP. Other major institutions using SSiB-based models in an offline mode and/or coupled to a parent atmospheric model include COLA, JMA, and UCLA.

$\mathrm{SSiB}$, however, had a deficiency in snow melt timing and meltwater infiltration, first noted by Robock et al. (1995). Several methods were undertaken to improve the simulation of these processes in SiB-based models (Xue et al., 1997; Sellers et al., 1996). However, when using the global ISLSCP Initiative I data within GSWP, significant snow-physics and meltwater infiltration deficiencies surfaced again (Mocko and Sud, 1998). In fact, the deficiencies were not unique to SSiB. Snow-physics testing and development for models has also been done in several land-surface schemes. Among these are Verseghy (1991), Douville et al. (1995), Yang et al. (1997), Loth and Graf (1998a), Liston and Sturm (1998), Desborough and Pitman (1998), Jin et al. (1999), Sun et al. (1999), and Smirnova et al. (2000). A summary of the current range of snow-physics packages within land-surface schemes is detailed in Slater et al. (2000). The current design benefited from several ideas and concepts discussed in the above papers and have adapted some of them for use in the model.

Huge deficiencies in snow melt and meltwater infiltration motivated the development of an earlier snow-physics scheme described in Sud and Mocko (1999). In this development, the snow layer was separated from the top soil layer. This separation allowed non-reflected shortwave energy to be absorbed in the snow, or to be transmitted through and absorbed in 
the soil, which had the effect of keeping the soil warm and "blanketed" under the snowpack. Once the snow melt began, the warmer non-frozen soil was able to infiltrate the meltwater before the entire snowmelt occurred. Larger meltwater infiltration was accompanied by larger GCM-simulated high northern latitudinal evapotranspiration and precipitation as observed in and around regions of strong seasonal snow cover (Mocko et al., 1999).

The primary motivation for additional improvements was to reduce the remaining biases in the onset of snow melt. Diagnostic tests revealed that the snow surface was not generating the amplitude of diurnal temperature that is observed in the early spring season to initiate mid-day melting. Consequently, snowpack slowly warmed until the entire snowpack reached the melting temperature at which time it started to melt precipitously. Thus, as compared to observations, there was delayed initiation of snowmelt, but once it started, it was relatively sudden. This gave the useful clue that deep snowpack needs a diurnal layer, and the only way to achieve this is by separating it from the rest of the pack. Accordingly, a two layer snow model was designed.

Besides the above, some other deficiencies in SSiB's hydrology and fluxes also became evident. For instance, SSiB had no provision for generating surface runoff as a function of orography. This motivated the development of an orography/runoff function. Similarly, modifications were needed to improve the sub-surface runoff (or baseflow). An empirical, but reasonable, interaction with the water table was also added. The removal of soil moisture by evaporation or transpiration can now occur from any soil layer, although a weighting function is in place to favor the previous formulations. These changes were made to improve both the simulated soil moisture and runoff as compared to available observations. Finally, skin temperatures were often too high in hot dry regions which motivated an examination 
and partial solution of this problem.

The goal of this research and development activity was to further improve the verifiable simulated results from $\mathrm{SSiB}$, especially with regards to the new snow-physics package. In addition to producing a realistic diurnal cycle of the snowpack, the intended changes were designed to improve the simulation of the snow accumulation and snow melt timing, meltwater infiltration, snow surface as well as soil temperatures, and runoff. A detailed description of all the improvements to the snow-physics in SSiB is found in Section 2. The simulated results from all three versions of SSiB (original - Xue et al., 1991, Sud and Mocko, 1999, and that described in this paper) are compared against each other and observations from 1987-1988 using the ISLSCP Initiative I data in Section 3. The same three model versions are also compared against observations using an 18-year catchment dataset from Valdai, Russia in Section 4. Conclusions and a discussion are found in Section 5.

\section{Changes from one snow layer version of SSiB}

This section describes the changes made from the one snow layer version of SSiB (Sud and Mocko, 1999 - OSL, hereafter) to the two snow layer version of SSiB (TSL, hereafter). The first sub-section describes additional improvements made to the snow model, while the following two sub-sections describe other changes related to the model's hydrology and flux calculations. Each improvement was separately evaluated.

\section{a. Changes to the snow model}

Reduced, yet systematic, delays of snow melt suggested the need for additional modifications of OSL (Figure 1). The deficiency was due to the inability of OSL to simulate a 
realistic diurnal temperature. Additionally, a very deep snowpack in the real world would not have a constant temperature over its entire depth, from near the insulated soil/snow interface to the surface which can radiate and cool freely. Thus a need for introducing a diurnal snow layer was evidenced.

\section{1) Diurnal Snow Layer}

In the TSL design, the number of prognostic temperature layers is maintained at three. Under a deep snowpack, there is no need for a diurnal soil layer because of the insulating effect of the snow and very little solar income. However, a diurnal snow layer emerges atop the snowpack, which can melt during the day due to strong solar input and can cool significantly at night, much more than the rest of the snow beneath this layer. So when the snow accumulates enough to activate the snow model (currently, the "trigger" is $0.005 \mathrm{~m}$, or $5 \mathrm{~mm}$, water equivalent), the snowpack is divided into two layers which start with the same temperatures, one for the bulk layer $\left(T_{s}\right)$ and one for the diurnal layer $\left(T_{s n}\right)$ of snow. In time, these two layers evolve differently through their own energy budget and heat exchange between them. The diurnal layer has a fixed depth of $Z_{s n}=0.004 \mathrm{~m}$ (4 $\mathrm{mm}$ ) water equivalent regardless of the total depth of snow, and the bulk layer is comprised of the remainder of the depth of the snowpack. For deep snow, the force-restore layer (Deardorff, 1978) is brought up to work with snow while the soil layers are joined into one $\left(T_{d}\right)$. Schematics showing the major design features of OSL and TSL are found in Figure 2.

Scientific justifications to moving the diurnal layer atop the snowpack are as follows. This top layer is able to respond to the diurnal changes of the atmosphere if the depth of the diurnal layer is chosen to best respond to these changes. Indeed, the top of the snow can 
cool radiatively at night, without replenishing all the energy by conduction from the bulk layer. Thus the diurnal layer works as an insulator for the bulk layer. The opposite holds for warm days, particularly with midday sun in the early spring. These warm days can produce snow melt in late winter/early spring, which was lacking in OSL. The prognostic equations for TSL are discussed in Appendix A.

The blended soil layer interacts with the bulk snowpack atop virtually the same way as in OSL. Heat is exchanged between the soil and snow layers through an assumed very thin air gap between them by radiation. This air gap functions to introduce a time scale of two or three hours in the exchange of heat between snow and soil. The incoming shortwave energy can be reflected, absorbed in the snow (in either of two snow layers) or transmitted through the snow and absorbed in the soil. The re-freezing of snow melt on the soil (if below the freezing temperature) which raises the soil heat, as well as the snow melt by ground heat flux are left essentially unchanged from OSL. The correction of invoking the saturation pressure over ice (rather than over water) with a snowpack is also unaltered. Also as in OSL, the scheme holds the snow fluxes constant for melting conditions; this eliminates fictitious warming of snow and its influence on saturation vapor pressure in the implicit backward solution. For details on these processes, see Sud and Mocko (1999).

\section{2) AGE EFFECT}

Having experimented with a few documented algorithms, the age effect of the snow on snow density following Verseghy (1991) is adopted. The snow density of the bulk snow layer is assumed to be constant with depth, and increases exponentially with time from the 
fresh snow value of $\rho_{s}$ MIN $=100 \mathrm{~kg} \mathrm{~m}^{-3}$ to $\rho_{s} \mathrm{MAX}=300 \mathrm{~kg} \mathrm{~m}^{-3}$, following:

$$
\rho_{s}(t+\Delta t)=\left(\rho_{s}(t)-\rho_{s} \mathrm{MAX}\right) \exp \left(-0.24 \frac{\Delta t}{\tau}\right)+\rho_{s} \mathrm{MAX}
$$

where $\rho_{s}$ is the density in $\mathrm{kg} \mathrm{m}^{-3}, \tau=86400 \mathrm{sec}$, and $\Delta t$ is the timestep in sec. The snow density can become more than $\rho_{s}$ MAX as a result of re-freezing of rain or meltwater, while fresh snowfall lowers the density via a weighted average of the old and new snow. The density of the diurnal snow layer is held at $119.6 \mathrm{~kg} \mathrm{~m}^{-3}$ so as to generate a constant depth diurnal layer, which is approximately the $\rho_{s}$ value from Eq. 1 after a 12-hour half-day period.

The snow density affects two main parameters of TSL. The snow thermal conductivity $\left(\kappa_{s}\right)$ is a strong function of the snow density. With some sensitivity experiments (not shown), it was found that making the snow conductivity a function of snow density has a large effect on the evolution of the snowpack. The form of the relation among the available has relatively little effect in test simulations, although Loth and Graf (1998b) did show an effect in a different set of experiments. Regardless, the following functional form is adopted in TSL due to Yen (1981):

$$
\kappa_{s}=\kappa_{i}\left(\frac{\rho_{s}}{\rho_{w}}\right)^{1.88}
$$

where $\kappa_{s}$ is the thermal conductivity of snow in $W m^{-1} K^{-1}, \kappa_{i}=2.22 W m^{-1} K^{-1}$ is the thermal conductivity of ice, and $\rho_{w}=1000 \mathrm{~kg} \mathrm{~m}^{-3}$ is the density of water. 


\section{3) Fractional SNOW COVER}

The fractional snow cover is also a function of the snow density, as well as of the snow depth. The water equivalent snow depth multiplied by the density of water and divided by the density of snow gives the depth of the snow. If the water equivalent snow depth is below $10 e^{-5} m$, the snow fraction is arbitrarily set to zero. Above $10 e^{-5} m$ depth, the snow cover fraction has a functional form:

$$
\begin{aligned}
\varepsilon & =\exp \left[-2\left(\frac{\alpha Z_{s t} \rho_{w}}{\rho_{s}}-\beta\right)\right] \\
\gamma & =-\frac{1-\exp (2 \beta)}{1+\exp (2 \beta)} \\
F_{s} & =\frac{\left(\frac{1-\varepsilon}{1+\varepsilon}\right)+\gamma}{1+\gamma}
\end{aligned}
$$

where $F_{s}$ is the fractional snow cover, $Z_{s t}$ is the total water equivalent snow depth in $m, \alpha$ is 35 , and $\beta$ is 2 . Figure 3 shows a few representative curves for fractional snow cover as a function of water equivalent snow depth based on snow density. This function in TSL is designed to increase the fraction slowly at first, then very rapidly before asymptoting to 1.0. The fractional snow cover then affects the four components of albedo (direct/diffuse, visible/near-IR) and the radiation absorption coefficients within SSiB. These radiation parameters are also affected by melting snow. If either the diurnal or bulk snow layer temperature is $>272.16$ $K$, the snow is considered to be in a melting phase or recently melted, which reduces the albedos and coefficients to $60 \%$ of their values. Similar assumptions were already used in SSiB. For details on how these parameters are calculated, see Xue et al. (1991) and Sellers et al. (1986). 


\section{4) DEeP SOIL TEMPERATURE}

Another significant change to the calculation of soil temperatures is in the bottom heat flux due to heat exchange with the infinite ground beneath, which happens regardless

of the snow cover. A calculation for heat exchange between the deep soil temperature, $T_{d}$, and a constant "very deep" soil temperature, $T_{d d}$, is added. A force-restore on an annual time scale determines the heat exchange and time rate of change of $T_{d}$ :

$$
\frac{\partial T_{d}}{\partial t}=\frac{2 \pi}{365 \tau}\left(T_{d d}-T_{d}\right)
$$

where $T_{d d}$ for each grid box was obtained by doing a multi-year average of $T_{d}$. Adding Eq. 6 to the model has the beneficial effect of improving the amplitude of the annual cycle of deep temperature; specifically, it cools the deep (and by extension, the diurnal soil temperature - $T_{g}$ ) layer during the summer, and warms the soil under the snowpack during the winter. The warmer soil temperature can produce or cause earlier melting and meltwater infiltration. This modification is physically based and the correction generally improves the simulation.

\section{b. Changes to the hydrology model}

\section{1) OROGRAPHY-BASED RUNOFF}

SSiB did not parameterize a dependence of overland flow for high orography. The need for this is evident, although it is difficult to design such a parameterization. In SSiB, the only two ways that surface flow could occur were: 1) soil wetness fractions exceeding 1.0 , or 2) due to a treatment of infiltration rates of precipitation (especially convective vs. 
large-scale) described in Sato et al. (1989). The function of the distribution equation is:

$$
P I(x)=\left(P_{c} a_{c}+P_{p} a_{p}\right) \exp ^{-b x}+\left(P_{c} c_{c}+P_{p} c_{p}\right)
$$

where $P_{c}$ and $P_{p}$ are the convective and large-scale precipitation rates (respectively) in $m m$ during the timestep, and $P I(x)$ can be interpreted as an amount distribution which is used to calculate throughfall and infiltration rates. The coefficients $(a, b, c)$ for convective and large-scale precipitation are recast to better match observed runoff values with simulated. The old and new values are shown in Table 1.

The runoff from melting snow cover, which had been excessively high in original SSiB, was systematically lessened in OSL. Additionally, the values of runoff were low compared to observations from many river basins in the annual time scale. Therefore, a hill-slope orography function is constructed which runs off a fraction of the available water ( $A W$ primarily, rainfall and meltwater) before it has a chance to enter the soil. The simplest functional form in which the runoff fraction is a function of the soil slope did not show much promise. However, with the availability of the GTOPO30 digital elevation model (DEM) orography heights at a horizontal grid spacing of 30 arc seconds, the runoff fraction is reformulated as a function of the standard deviation of the orography height $\left(\sigma_{h}\right)$ in each 1 deg. by 1 deg. grid box. The $\sigma_{h}$ was calculated from the height at each grid box in the GTOPO30 DEM to the mean of the DEM heights in the 1 deg. box. After a global map of $\sigma_{h}$ was constructed, the annual runoff deficit (observed runoff minus modeled runoff from OSL) was calculated for nearly 30 river basins around the globe with observed runoff data for 1987-1988 and a sufficient number of rain gauges in the basin (after Oki et al., 1999). 
Next, the water available for runoff ( $A W$ - precipitation plus meltwater minus snowfall) was calculated for the same basins on an annual basis. These values are shown on a scatter plot, with the $\sigma_{h}$ scaled by $\sigma_{h} \mathrm{MAX}=1843.47 \mathrm{~m}$, and the runoff deficit scaled by $A W$. To reduce the potential dominance of a few grid boxes in the basin, the $\sigma_{h}$ was weighted by the $A W$ at each grid box, then averaged over the basin, then divided by the basin-averaged $A W$. A fit is drawn to this scattered data and is shown in Figure 4. The final form of the function for orography-aided surface runoff is:

$$
\mathrm{AR}=\min \left[\left(2.07 * \frac{\sigma_{h}}{\sigma_{h \mathrm{MAX}}}\right), 0.5\right] * A W
$$

where $A W$ can be the available water at any time during the model timestep, and $A R$ is the additional runoff generated. The precipitation contribution to $A W$ is calculated after the runoff produced via Eq. 7, and the meltwater contribution to $A W$ does not include re-freeze.

\section{2) LiNEAR RESERVOIR DRAINAGE}

Some improvements are also made to the linear reservoir drainage of SSiB. Liston et al. (1994) introduced a calculation for discharge from the bottom layer that accounts for the spatial variability of the grid box. This equation has been recast as:

$$
B F=\left(\frac{\Delta t}{365 \tau}\right)\left(W_{3}-W_{\text {wilt }}\right) P Z_{3}
$$

where $B F$ is the sub-surface runoff (or baseflow) in $m$ from soil layer 3 during the timestep, $W_{3}$ is the soil wetness of layer $3, W_{\text {wilt }}$ is the wilting point wetness (see Mocko and Sud, 1998), $P$ is the soil porosity, and $Z_{3}$ is the depth of soil layer 3 in $m$. If $W_{3}$ is below $W_{\text {wilt }}$, 
baseflow does not occur.

\section{3) Gravitational Drainage}

The gravitational drainage in SSiB is also modified accordingly. The equation essentially is unchanged, other than the drainage had been the minimum of Sellers et al. (1986, Eq. 62) and $W_{3} P Z_{3} / \Delta t$, and now the minimum has been replaced by $\left(W_{3}-W_{\text {grav }}\right) P Z_{3} / \Delta t$, where:

$$
W_{\mathrm{grav}}=\left(\frac{\psi_{s}-0.5 Z_{3}}{\psi_{s}}\right)^{-\frac{1}{B}}
$$

is the wetness at which $Z_{3}$ is half-saturated, $\psi_{s}$ is the soil moisture potential at saturation in $m$, and $B$ is the Clapp and Hornberger (1978) parameter. If $W_{3}$ is below $W_{\text {grav }}$, this half of the minimum is zero, and gravitational drainage does not occur.

\section{4) WATER TABLE INTERACTION}

An important change to SSiB's hydrology is the addition of a water table interaction below soil layer 3 . If $W_{3}$ happens to drop below $W_{\text {wilt }}$, a factor is put into place such that half of this loss during the timestep is replaced by the water table. Because the assumption had been made that the water table height is at the level of the bottom of soil layer 3 , the baseflow and gravitational drainage described above will move water back from $W_{3}$ to the water table during wet periods. An elementary parameterization of the effects of a rising and falling water table is thus introduced to keep the very deep soil from going too dry (wet) in a prolonged drought (rainy) period. 
c. Changes to the calculation of SSiB fluxes

\section{1) BARE SOIL EVAPORATION}

Several changes are made to the way SSiB calculates surfaces fluxes and how the soil responds to these fluxes. The bare soil evaporation and transpiration rates calculated by $\mathrm{SSiB}$ have remained the same; however, the depth at which the water is removed from the soil has been changed. For bare soil evaporation, the water can now be removed from any of the three layers - on the assumption that scattered capillaries of various shapes and forms (non-water areas) in the soil allow water from the lower layers to pass through to the surface. The extraction from each of the three layers is weighted by the fractional weight for each layer, divided by the sum of the three weights. The weights $\left(W T B_{i}\right)$ for each of the three layers are:

$$
\begin{aligned}
W T B_{1}= & \exp \left[\left(\frac{\psi_{s} g}{R_{v} T_{g}}\right) * W_{1}^{-B}\right] \\
W T B_{2}= & \left(1.0-W T B_{1}\right)\left(\frac{2 Z_{1}}{2 Z_{1}+Z_{2}}\right) \exp \left[\left(\frac{\psi_{s} g}{R_{v} T_{g}}\right) * W_{2}^{-B}\right] \\
W T B_{3}= & \left(1.0-W T B_{1}-W T B_{2}\right)\left(\frac{2 Z_{1}}{2 Z_{1}+2 Z_{2}+Z_{3}}\right) \\
& * \exp \left[\left(\frac{\psi_{s} g}{R_{v} T_{g}}\right) * W_{3}^{-B}\right]
\end{aligned}
$$

where $g=9.81 \mathrm{~m} \mathrm{sec}^{-2}$ is the acceleration due to gravity at the earth's surface, $R_{v}=461.5$ $J K^{-1} \mathrm{~kg}^{-1}$ is the water vapor gas constant, $Z_{i}$ and $W_{i}$ is the depth over soil layer $i$ and soil wetness of layer $i$ respectively, and $T_{g}$ is the top SSiB soil layer temperature. Although some soil water extraction can now be realized from layers 2 and 3 , the majority of the weighting still takes bare soil evaporation loss from soil layer 1. 


\section{2) EXTRACTION BY TRANSPIRATION}

The extraction of water from the soil that is used in transpiration is similarly modified with a weighted fraction taken for each of the layers containing vegetation roots. Additionally, the weight for each layer $\left(W T T_{i}\right)$ is zero if the soil moisture potential of that layer $\left(\psi_{i}\right)$ is less than a minimum of soil moisture potential $\left(\psi_{\text {low }}\right)$. These weights are calculated as:

$$
\begin{aligned}
\psi_{i} & =\psi_{s} W_{i}^{-B} \\
\psi_{\text {low }} & =\psi_{s} W_{\text {wilt }}^{-B} \\
W T T_{i} & =\left(\psi_{i}-\psi_{\text {low }}\right) * Z_{i} \text { ROOT }
\end{aligned}
$$

where $Z_{i \text { ROOT }}$ is the depth of layer $i$ which contains roots. The parameter $\psi_{\text {low }}$ also is used as a minimum when calculating the stomatal resistance parameter shown in Xue et al. (1991, Eq. 9).

\section{3) BuOYANCY VELOCITy SCALE}

The bulk aerodynamic formula for the sensible heat flux in SSiB is modified, after Mahrt and Sun (1995, Eqns. 11 and 12). The new formula includes a "buoyancy velocity scale" defined by:

$$
w_{B}=\left(\frac{g}{\theta_{v}} z_{i} \Delta \theta_{B}\right)^{1 / 2}
$$

where $z_{i}$ is the boundary layer depth in $m$, and $\Delta \theta_{B}$ is the difference between the virtual potential temperature at the surface $\left(\theta_{v}\right)$ and the virtual potential temperature of the mixed 
layer. Their buoyancy velocity scale is added to SSiB's wind speed at reference height $M$ as:

$$
M=M+\left(2 b_{H} w_{B} C_{T N}^{-1} C_{U N}^{-1}\right)
$$

where $b_{H}=0.00025$, and $C_{T N}$ and $C_{U N}$ are SSiB's neutral heat and neutral momentum transfer coefficients, respectively. This is done for unstable cases only before the calculation of the aerodynamic resistance between the canopy air space and the reference height. The minimum reference height wind speed is also changed from $2.0 \mathrm{~m} \mathrm{sec}^{-1}$ to $0.1 \mathrm{~m} \mathrm{sec}^{-1}$. This is a physically-based upgrade and it has the benefit of increasing sensible heat flux and leading to some cooling of anomalously large skin temperatures over hot dry desert regions in $\mathrm{SSiB}$.

Two other changes are made to the SSiB flux calculations. The first is that SSiB biome type 11 (desert) in previous versions did not explicitly calculate the stomatal resistance, whereas TSL does. The second is that the maximum stomatal resistance for the canopy layer for any biome type (and the constant value for all ground story layers) is changed from $1.0 e 5$ to $1.0 e 10$. These changes allow $\mathrm{SSiB}$ a wider range to calculate the stomatal resistance on its own (especially for desert) reducing the influence of an arbitrary cutoff.

\section{Results with GSWP Global data}

The upgraded version of the snow-physics scheme with SSiB was integrated globally for 1987-1988 using the $1 \mathrm{deg}$. by $1 \mathrm{deg}$. ISLSCP Initiative I data after a ten-year soil moisture spin-up procedure. The detailed procedure followed is the same as for previous versions of $\mathrm{SSiB}$, and is detailed in Dirmeyer et al. (1999). Again, the Russia Wheat Belt region (55 - 
$65 \mathrm{~N} ; 20-60 \mathrm{E}$ ) is a particular area of focus because of the availability of observations of soil moisture and runoff in this area.

Northern Hemisphere observations of snow cover from satellite are also available through the ISLSCP Initiative I dataset. The weekly data is retrieved from NOAA satellites and is simply a function of snow or no snow cover at the grid box. By taking an area-averaged time series of observed snow cover of this region, and comparing it to similar curves from the simulated model data, as shown in Figure 5, one can see that TSL does a better job of simulating snow melt timing. In addition, TSL also captures some of the mid-winter snow melt in Jan 1988 that previous versions did not. This benefit results from the diurnal layer of the snowpack which is able to melt realistically during warm winter episodes.

Over this time period, there are two useful soil moisture validation datasets. One, a portion of which includes the Russia Wheat Belt region, is described by Vinnikov and Yeserkepova (1991); the other, in the state of Illinois in the central United States, is described by Hollinger and Isard (1994). The time resolution of these data are generally a week to ten days; however, the Russian data is not available in winter due to soil freezing. This data is compared against the simulated soil moisture data in terms of available water in the top meter of the soil, which is simply the total water in the top meter, minus the soil's wilting point value. The simulated vs. observed values are shown in Figure 6. In the top part of the figure for the Russian region, the effect of the soil moisture spin-up is clearly seen as TSL has wetter soil than the original. TSL also better reproduces the spring rise in soil moisture due to meltwater infiltration, followed by drying in the summer from evapotranspiration. OSL also produces a spring rise, but it is delayed after the peak in the observations. In the bottom part of the figure for Illinois, where there is relatively little meltwater generated and 
the change in the snow-physics has relatively little effect, the simulated soil moisture from TSL, OSL, and original SSiB compare well with observations. All versions capture the wet 1987 and dry 1988 in Illinois. However, TSL is relatively wetter on the annual time scale in better agreement with the observations. In addition, TSL has the wettest late summer and fall, showing the beneficial effects of the water table interaction.

The simulated against observed basin-scale runoff is also a worthy tool to validate a land-surface scheme. However, to be truly useful, the simulated runoff should be routed through a river routing scheme. The simulated runoff by all three versions of the model were separately routed using the TRIP river routing due to Oki and Sud (1998) and used in Oki et al. (1999). The TRIP-routed runoff for two river basins compared to observations from stream flow is shown in Figure 7. These basins were chosen because they had available river gauge observations that were close to the soil moisture regions defined in Figure 6. The top part of the figure shows the simulated and observed flow in the Volga River, which is in the Russia Wheat Belt region. One can see the spuriously high and late runoff in original SSiB. TSL has an earlier spring peak in the flow (from meltwater) than OSL. The bottom of the figure is in the Mississippi River Basin in the central United States. The annual flow is generally similar to OSL, except the June to October flow is higher as a result of the modifications to baseflow.

Another useful land-surface scheme validation variable is skin temperature. This value can be retrieved from satellite, where it is measured over the satellite pixel size, or simulated by a model, where it is the spatial average of the vegetation and soil skin temperatures weighted by the fractional vegetation cover. A useful satellite dataset for this time period is TOVS Pathfinder Path A due to Susskind et al. (1997). The skin temperature differences 
between the model simulated values and the satellite retrievals are shown in Figure 8 . The upper right panel clearly shows a cold bias in the Northern Hemisphere in original SSiB. This is from snow cover being simulated in the model but not observed. OSL in the lower left panel removes most of this error, but the closest values to observations are found in TSL shown in the lower right panel. Especially in the Russia Wheat Belt region and northwestern Canada, TSL is closer than OSL in the simulated skin temperature comparison.

Additionally, adding the Mahrt and Sun (1995) buoyancy velocity scale to the surface wind speed has the effect of partially mitigating a warm bias in surface temperatures between OSL and TSL in hot dry regions. A closer look at this result is shown in Figure 9, where in regions of the Sahara, Australia, and the western United States, the skin temperatures have cooled by about a degree. Other areas of cooling are found in India and the Middle East in northern winter (not shown). This calculation uses arbitrary constants and can be improved to produce better results.

\section{Results with VALDAI region data}

All three versions of the SSiB were integrated using an 18-year single-site dataset from Valdai, Russia. This dataset, which is described in Vinnikov et al. (1996) and Schlosser et al. (1997), is a midlatitude grassland and was used for PILPS Phase 2(d) (Schlosser et al., 2000). The years of the simulation are 1966-1983 and the area is noted for its deep snowpack in winter, followed by a strong spring melt. The data used are from the Usadievskiy catchment at Valdai where the long-term measurements were taken. Before the 18-year simulation began, each version's initial soil moisture was separately spun-up using the 1966 forcing data until the soil moisture reached quasi-equilibrium. 
The annual cycle of snow accumulation and snow melt is shown in Figure 10. The observations, which are recorded monthly (and after snow events and frequently during snow melt) are shown in circles. As in the GSWP simulations, original SSiB simulates much delayed snow melt, and TSL has the earliest snow melt. There is some indication that TSL may be melting snow too early, although it is difficult to isolate a systematic bias. A better picture of this early melt is shown in Figure 11, which is a time series over the entire 18 years. For many spring melt periods, TSL is too early. However, TSL does well for some years in simulating the maximum snow depth, certainly no worse than OSL. TSL is also shown to have periods of mid-winter melt, doing a particularly nice job of reproducing the winter 1971 snow depth. The early melt in some winters in Valdai may be sensitive to arbitrarily chosen values for $T_{d d}, \rho_{s}$ for the diurnal layer, or $\kappa_{t}$ given before or in Appendix A. Additionally, the simulated snow albedo by all three versions is around 0.61 , where the observed value at this site is around 0.75 (Robock et al., 1995). A too low albedo causes additional solar energy absorption in the snow and soil and results in incorrectly early melt. The calculation of SSiB's snow albedos will be a focus of future research.

TSL does a better job of simulating the annual cycle of soil moisture as shown in Figure 12. The spring rise and March peak in soil moisture due to meltwater infiltration is captured quite well. The peak from OSL is too late, while original SSiB is too dry all year with no spring soil moisture peak. TSL (as well as OSL and original SSiB) is too dry in late summer, in part due to too high evapotranspiration (shown later). Still, the annual average simulated soil moisture is highest with TSL. The 18-year time series of soil moisture is seen in Figure 13. Of particular interest is the simulated soil moisture profiles for the years 1976-1977. TSL keeps the soil moisture wetter as observed for these two years. Evidently, 
the spring 1976 rise in soil moisture, well reproduced by TSL, wettens the soil and is kept at this wetness for this period.

The annual averaged runoff at the Valdai location is shown in Figure 14. These catchment discharges are not routed through TRIP, as the region is sufficiently small. As before, the runoff from original $\mathrm{SSiB}$ is too high and too late in the season. OSL has a very low spring soil moisture peak. In TSL, there is a strong initial peak in the runoff, but this drops off suddenly. The late summer and fall runoff is reproduced well, but the annual average of TSL is too low for this region. This may be caused by too high simulated evapotranspiration.

The annual cycle of evapotranspiration is shown in Figure 15. TSL well simulates the early spring evapotranspiration, as a result of the earlier snow melt and meltwater infiltration. However, the summer evapotranspiration in TSL is too high. This change is a combination of higher early summer soil moisture (as observed) and the modifications to SSiB described earlier.

Figure 16 shows the annual cycle of simulated $\mathrm{SSiB}$ deep temperature $\left(T_{d}\right)$ against the observed soil temperature at $80 \mathrm{~cm}$ below the surface. The original model, which had the coupled snow/soil layer, is unrealistically cold during the winter. TSL has the smallest annual amplitude in better agreement with observations. This suggests the addition of $T_{d d}$ to an annual cycle of force-restore of the deep soil temperature is a useful modification.

\section{Conclusion and discussions}

Overall, the upgraded snow-physics package, along with other improvements to SSiB, has been shown to improve SSiB's simulation of snow depth, meltwater infiltration, runoff, 
and soil temperatures. Both in the Russia Wheat Belt region and the Valdai simulation, the model's improved physics lead to a better simulation of temperatures, which results in earlier melt and well-simulated soil moistures.

Some problems still remain, however. For one, the model may now be melting too early in some regions. The snow melt timing is intimately related to diurnal snow layer properties and its thickness. Values taken for $\rho_{s}, \kappa_{t}$, and albedo, which are kept constant everywhere, deserve more attention (e.g., Loth and Graf, 1998b). Also, the values taken for $T_{d d}$ have a large effect on the soil temperature under the snowpack and thus the initiation of snow melt. The formulation of fractional snow cover and the effect of melting snow on albedo also seem to play an influential role, and better parameterizations for these processes need to be instituted. In addition, adding the effects of blowing snow (Liston and Sturm, 1998), solar absorption by snow on sloped surfaces, and sub-grid snow cover effects (Liston, 1999) are expected to affect the simulation.

Additional multi-year validation datasets are needed to test the model. In addition to useful single-site datasets such as Valdai, longer time period global datasets would be useful to test the model at many different locations and times. The upcoming GSWP 1.5 and GSWP 2 (using ISLSCP Initiative II data) projects are expected to lead to further opportunities to evaluation and improve SSiB's snow-physics and hydrology.

SSiB has also been coupled to a very high resolution soil hydrology model for detailed soil moisture profiles. In its current form, 100 soil moisture layers of $5 \mathrm{~cm}$ thickness for a total depth of $5 \mathrm{~m}$ are used within $\mathrm{SSiB}$ to improve simulation of the inter-layer exchanges of water. Very often, the water table is above this $5 m$ depth, so the water table interaction is explicitly resolved. A soil model such as this may lead to improved parameterizations in 
the three layer $\mathrm{SSiB}$, and improve the simulation of evapotranspiration and baseflow.

\section{APPENDIX A}

The prognostic equations for the three levels of the two snow layer model of SSiB (TSL) are described in this appendix. The subscripts used in this section refer to the layers as follows: $s n=$ thin diurnal skin layer of snowpack, $s=$ bulk snowpack layer, and $d=$ blended soil and deep soil under snowpack. The prognostic equation for the diurnal, or top, snow layer is:

$$
C_{s n} \frac{\partial T_{s n}}{\partial t}=R_{n(s n)}-H_{s n}-\lambda E_{s n}-\frac{2 \pi C_{s n}}{\tau}\left(T_{s n}-T_{s}\right)
$$

where $C_{s n}$ is the effective heat capacity, $R_{n(s n)}$ is the net radiation, $H_{s n}$ is the sensible heat flux, $\lambda E_{s n}$ is the latent heat flux (where $\lambda$ is the latent heat of vaporization), and $\tau=86400$ sec. The sensible and latent heat fluxes are the same as Xue et al. (1991, Eqns. A5 and A6), other than $T_{g s}$ and $e_{*(g s)}$ are replaced by $T_{s n}$ and $e_{*(s n)}$.

The prognostic equation for the bulk snow layer is:

$$
C_{s} \frac{\partial T_{s}}{\partial t}=R_{n(s)}+\kappa_{c}\left(T_{d}-T_{s}\right)+\frac{2 \pi C_{s n}}{\tau}\left(T_{s n}-T_{s}\right),
$$

where $C_{s}$ and $R_{n(s)}$ are the effective heat capacity and net radiation of the bulk layer, and $\kappa_{c}$ is the snow/soil interface conductivity (given later).

The prognostic equation for the blended soil and deep soil under the snowpack is:

$$
C_{d} \frac{\partial T_{d}}{\partial t}=R_{n(d)}-\kappa_{c}\left(T_{d}-T_{s}\right)+\frac{2 \pi}{365 \tau}\left(T_{d d}-T_{d}\right),
$$


where $C_{d}$ and $R_{n(d)}$ is the effective heat capacity of the soil and net radiation of the soil.

The net radiations for all three levels with snowpack are:

$$
\begin{aligned}
R_{n(s n)}= & S W_{\downarrow}(1-\alpha)\left[1-\exp \left(-\kappa_{t} Z_{s n}\right)\right]+L W_{\downarrow}\left[1-V_{c}\left(1-\epsilon_{c}\right)\right] \\
& +\sigma_{s} T_{c}^{4} V_{c}\left(1-\epsilon_{c}\right)-\sigma_{s} T_{s n}^{4}, \\
R_{n(s)}= & {\left[S W_{\downarrow}(1-\alpha)-R_{n(s n)}\right]\left(1-\exp \left(-\kappa_{t} Z_{s}\right)\right), } \\
R_{n(d)}= & S W_{\downarrow}(1-\alpha)-R_{n(s n)}-R_{n(s)},
\end{aligned}
$$

where $S W_{\downarrow}(1-\alpha)$ is the sum of all four components (direct/diffuse, visible/near-IR) of the shortwave incident on the top of the snowpack and not reflected ( $\alpha$ is the albedo), $L W_{\downarrow}$ is the longwave incident on the top of the snowpack, $Z_{s n}=0.004 \mathrm{~m}(4 \mathrm{~mm})$ is the water equivalent depth of the diurnal snow layer, $Z_{s}$ is the water equivalent depth of the bulk snow layer, $\sigma_{s}=8.76 \times 10^{8} \mathrm{~W} \mathrm{~m}^{-2} \mathrm{~K}^{-4}$ is the Stefan-Boltzmann constant, $T_{c}$ is the canopy temperature in $K, V_{c}$ is the fractional cover of the canopy vegetation, and $\epsilon_{c}$ is the longwave emissivity. The transmittance coefficient for shortwave energy through the snow is $\kappa_{t}=25.0$, which is the same as in Sud and Mocko (1999, Eq. 1). This value allows $10 \%$ of the incoming non-reflected solar to transmit through $10 \mathrm{~cm}$ of snow/ice.

The blended conductivity of heat for the snow/soil interface - which conducts heat through the layers to the interface and radiates heat through a small assumed air-gap between the layers is:

$$
\kappa_{c}=1 /\left(\frac{0.5(1+\sqrt{365}) Z_{1}}{\kappa_{d}}+\frac{1}{4 \sigma_{s}\left(\frac{T_{s}+T_{d}}{2}\right)^{3}}+\frac{0.5 Z_{s} \rho_{w}}{\kappa_{s} \rho_{s}}\right)
$$


where $\kappa_{d}$ is the thermal conductivity of the soil, and $\kappa_{s}$ is the thermal conductivity of snow defined in Eq. 2.

The above equations are solved in a implicit backward method given in Sellers et al. (1986) and explained in more detail for use with snow-physics in Sud and Mocko (1999). Other than the introduction of the very deep temperature equation (Eq. 6), the prognostic equations for temperatures for snow-free land remain the same in $\mathrm{SSiB}$ due to Xue et al. (1991).

\section{Acknowledgments}

The authors wish to thank Kenneth Bergman of NASA Headquarters and Rick Lawford of NOAA's Office of Global Programs for supporting this research. Thanks to Adam Schlosser for use of the PILPS 2(d) Valdai forcing data. Thanks also to Taikan Oki for use of the TRIP river routing model and to Joel Susskind for use of the TOVS Pathfinder A data. Thanks as well to Alan Robock, Steve Hollinger, and Konstantin Vinnikov for use of the soil moisture data. The GTOPO30 DEM data are distributed by the EROS Data Center Distributed Active Archive Center (EDC DAAC), located at the U.S. Geological Survey's EROS Data Center in Sioux Falls, South Dakota. Streamflow data of major river basins, Ver. 0, Dept. of Hydrology and Water Resources, University of Arizona, in cooperation with Dr. Wolfgang Grabs of the Global Runoff Data Center, Koblenz, Germany. NOAA Weekly Snow and Ice Cover Charts are produced and digitized by NOAA personnel. Quality control of the data set, including limited adjustments to the files for standardization purposes, has subsequently been conducted at Rutgers University by Dr. David A. Robinson. 


\section{REFERENCES}

Chen, F., K. Mitchell, J. Schaake, Y. Xue, H.-L. Pan, V. Koren, Q. Y. Duan, M. Ek, and A. Betts, 1996: Modeling of land surface evaporation by four schemes and comparison with FIFE observations. J. Geophys. Res., 101(D3), 7251-7268.

Chen, T. H., A. Henderson-Sellers, P. C. D. Milly, A. J. Pitman, A. C. M. Beljaars, J. Polcher, F. Abramopoulos, A. Boone, S. Chang, F. Chen, Y. Dai, C. E. Desborough, R. E. Dickinson, L. Dümenil, M. Ek, J. R. Garratt, N. Gedney, Y. M. Gusev, J. Kim, R. D. Koster, E. A. Kowalczyk, K. Laval, J. Lean, D. Lettenmaier, X. Liang, J.-F. Mahfouf, H.-T. Mengelkamp, K. E. Mitchell, O. N. Nasonova, J. Noilhan, A. Robock, C. Rosenzweig, J. Schaake, C. A. Schlosser, J.-P. Schulz, Y. Shao, A. B. Shmakin, D. L. Verseghy, P. Wetzel, E. F. Wood, Y. Xue, Z.-L. Yang, and Q. Zeng, 1997: Cabauw experimental results from the Project for Intercomparison of Land-surface Parameterization Schemes. J. Climate, 10(6), 1194-1215.

Clapp, R. B., and G. M. Hornberger, 1978: Empirical equations for some soil hydraulic properties. Water Resour. Res., 14(4), 601-604.

Deardorff, J. W., 1978: Efficient prediction of ground surface temperature and moisture, with inclusion of a layer of vegetation. J. Geophys. Res., 83(C4), 1889-1903.

Desborough, C. E., and A. J. Pitman, 1998: The BASE land surface model. Glob. and Plan. Change, 19, 3-18.

Dirmeyer, P. A., A. J. Dolman, and N. Sato, 1999: The pilot phase of the Global Soil Wetness Project. Bull. Amer. Meteor. Soc., 80(5), 851-878.

Douville, H., J.-F. Royer, and J.-F. Mahfouf, 1995: A new snow parameterization for the Météo-France climate model. Part I: valdiation in stand-alone experiments. Clim. Dyn., 12, 21-35.

Henderson-Sellers, A., Z.-L. Yang, and R. E. Dickinson, 1993: The Project for Intercomparison of Land-surface Parameterization Schemes. Bull. Amer. Meteor. Soc., 74(7), $1335-1349$.

Hollinger, S. E., and S. A. Isard, 1994: A soil moisture climatology of Illinois. J. Climate, $7(5), 822-833$.

Jin, J. M., X. G. Gao, S. Sorooshian, Z.-L. Yang, R. Bales, R. E. Dickinson, S. F. Sun, and G. X. Wu, 1999: One-dimensional snow water and energy balance model for vegetated surfaces. Hydrol. Process., 13, 2467-2482.

Liston, G. E., 1999: Interrelationships among snow distribution, snowmelt, and snow cover depletion: Implications for atmospheric, hydrologic, and ecologic modeling. J. Appl. Meteor., 38(10), 1474-1487.

Liston, G. E., and M. Sturm, 1998: A snow-transport model for complex terrain. J. Glaciol., 44(148), 498-516.

Liston, G. E., Y. C. Sud, and E. F. Wood, 1994: Evaluating GCM land surface hydrology parameterizations by computing river discharges using a runoff routing model: Application to the Mississippi Basin. J. Appl. Meteor., 33(3), 394-405. 
Loth, B., and H.-F. Graf, 1998a: Modeling the snow cover in climate studies. 1. Long-term integrations under different climatic conditions using a multilayered snow-cover model. J. Geophys. Res., 103(D10), 11313-11327.

Loth, B., and H.-F. Graf, 1998b: Modeling the snow cover in climate studies. 2. The sensitivity to internal snow parameters and interface processes. J. Geophys. Res., 103(D10), $11329-11340$.

Mahrt, L., and J. Sun, 1995: The subgrid velocity scale in the bulk aerodynamic relationship for spatially averaged scalar fluxes. Mon. Wea. Rev., 123(10), 3032-3041.

Meeson, B. W., F. E. Corprew, J. M. P. McManus, D. M. Myers, J. W. Closs, K.-J. Sun, D. J. Sunday, and P. J. Sellers, 1995. ISLSCP Initiative I - Global Data Sets for Land-Atmosphere Models, 1987-1988. Volumes 1-5. Published on CD by NASA (USA_NASA_GDAAC_ISLSCP_001 - USA_NASA_GDAAC_ISLSCP_005).

Mocko, D. M., and Y. C. Sud, 1998: Comparison of a land-surface model (SSiB) to three parameterizations of evapotranspiration - a study based on ISLSCP Initiative I data. Earth Interactions, 2, 40 pp. [Available online at http://EarthInteractions.org.].

Mocko, D. M., G. K. Walker, and Y. C. Sud, 1999: New snow-physics to complement SSiB. Part II: Effects on soil moisture initialization and simulated surface fluxes, precipitation, and hydrology of GEOS II GCM. J. Meteor. Soc. Japan, 77(1B), 349-366.

Oki, T., T. Nishimura, and P. Dirmeyer, 1999: Assessment of annual runoff from land surface models using Total Runoff Integrating Pathways (TRIP). J. Meteor. Soc. Japan, 77(1B), 235-255.

Oki, T., and Y. C. Sud, 1998: Design of Total Runoff Integrating Pathways (TRIP) - a global river channel network. Earth Interactions, 2, 53 pp. [Available online at http://EarthInteractions.org.].

Robock, A., K. Y. Vinnikov, C. A. Schlosser, N. A. Speranskaya, and Y. Xue, 1995: Use of midlatitude soil moisture and meteorological observations to validate soil moisture simulations with biosphere and bucket models. J. Climate, 8(1), 15-35.

Sato, N., P. J. Sellers, D. A. Randall, E. K. Schneider, J. Shukla, J. L. Kinter, Y.-T. Hou, and E. Albertazzi, 1989: Implementing the Simple Biosphere Model (SiB) in a general circulation model: Methodologies and results. 185509, NASA Contractor Report. 76 pp.

Schlosser, C. A., A. Robock, K. Y. Vinnikov, N. A. Speranskaya, and Y. Xue, 1997: 18year land-surface hydrology model simulations for a midlatitude grassland catchment in Valdai, Russia. Mon. Wea. Rev., 125(12), 3279-3296.

Schlosser, C. A., A. G. Slater, A. Robock, A. J. Pitman, K. Y. Vinnikov, A. HendersonSellers, N. A. Speranskaya, K. Mitchell, and the PILPS 2(d) Contributors, 2000: Simulations of a boreal grassland hydrology at Valdai, Russia: PILPS Phase 2(d). Mon. Wea. Rev., 128(2), 301-321.

Sellers, P. J., B. W. Meeson, J. Closs, J. Collatz, F. Corprew, D. Dazlich, F. G. Hall, Y. Kerr, R. D. Koster, S. Los, K. E. Mitchell, J. McManus, D. Myers, K.-J. Sun, and P. Try, 1995. An overview of the ISLSCP Initiative I Global Data Sets. On: 
ISLSCP Initiative I — Global Data Sets for Land-Atmosphere Models, 1987-1988. Volumes 1-5. Published on CD by NASA. Volume 1: USA_NASA_GDAAC_ISLSCP_001, OVERVIEW.DOC.

Sellers, P. J., Y. Mintz, Y. C. Sud, and A. Dalcher, 1986: A Simple Biosphere model (SiB) for use within general circulation models. J. Atmos. Sci., 43, 505-531.

Sellers, P. J., D. A. Randall, G. J. Collatz, J. A. Berry, C. B. Field, D. A. Dazlich, C. Zhang, G. D. Collelo, and L. Bounoua, 1996: A revised land surface parameterization (SiB2) for atmospheric GCMs. Part I: Model formulation. J. Climate, 9(4), 676-705.

Slater, A. G., C. A. Schlosser, C. E. Desborough, A. J. Pitman, A. Henderson-Sellers, A. Robock, K. Y. Vinnikov, K. Mitchell, A. Boone, H. Braden, F. Chen, P. M. Cox, P. de Rosnay, R. E. Dickinson, Y.-J. Dai, Q. Y. Duan, J. Entin, P. Etchevers, N. Gedney, Y. M. Gusev, F. Habets, J. Kim, V. Koren, E. Kowalczyk, O. N. Nasonova, J. Noilhan, J. Schaake, A. B. Shmakin, T. G. Smirnova, D. Verseghy, P. Wetzel, Y. Xue, Z.-L. Yang, and Q. Zeng, 2000: The representation of snow in land-surface schemes; Results from PILPS 2(d). J. Hydrometeor., ???, submitted.

Smirnova, T. G., J. M. Brown, S. G. Benjamin, and D. Kim, 2000: Parameterization of cold-season processes in the MAPS land-surface scheme. J. Geophys. Res., 105(D3), 4077-4086.

Sud, Y. C., and D. M. Mocko, 1999: New snow-physics to complement SSiB. Part I: Design and evaluation with ISLSCP Initiative I datasets. J. Meteor. Soc. Japan, 77(1B), 335348.

Sun, S. F., J. M. Jin, and Y. Xue, 1999: A simple snow-atmosphere-soil transfer model. J. Geophys. Res., 104(D16), 19587-19597.

Susskind, J., P. Piraino, L. Rokke, L. Iredell, and A. Mehta, 1997: Characteristics of the TOVS Pathfinder Path A dataset. Bull. Amer. Meteor. Soc., 78(7), 1449-1472.

Takacs, L. L., A. Molod, and T. Wang, 1994: Documentation of the Goddard Earth Observing System (GEOS) General Circulation Model - Version 1. 104606, NASA Technical Memorandum. Volume 1, 100 pp.

Verseghy, D. L., 1991: CLASS - a Canadian LAnd Surface Scheme for GCMs. I. Soil model. Int. J. of Clim., 11, 111-133.

Vinnikov, K. Y., A. Robock, N. A. Speranskaya, and C. A. Schlosser, 1996: Scales of temporal and spatial variability of midlatitude soil moisture. J. Geophys. Res., 101, 7163-7174.

Vinnikov, K. Y., and I. B. Yeserkepova, 1991: Soil moisture: Empirical data and model results. J. Climate, 4(1), 66-79.

Xue, Y., 1997: Biosphere feedback on regional climate in tropical north Africa. Quart. J. Roy. Meteor. Soc., 123, 1483-1515.

Xue, Y., H. G. Bastable, P. A. Dirmeyer, and P. J. Sellers, 1996: Sensitivity of simulated surface fluxes to changes in land surface parameterizations - a study using ABRACOS data. J. Appl. Meteor., 35(3), 386-400. 
Xue, Y., P. J. Sellers, J. L. Kinter, and J. Shukla, 1991: A Simplified Biosphere model for global climate studies. J. Climate, 4(3), 345-364.

Xue, Y., P. J. Sellers, F. J. Zeng, and C. A. Schlosser, 1997: Comments on "Use of midlatitude soil moisture and meteorological observations to validate soil moisture simulations with biosphere and bucket models". J. Climate, 10(2), 374-376.

Xue, Y., F. J. Zeng, and C. A. Schlosser, 1996: SSiB and its sensitivity to soil properties - a case study using HAPEX-Mobilhy data. Glob. and Plan. Change, 13, 183-194.

Yang, Z.-L., R. E. Dickinson, A. Robock, and K. Y. Vinnikov, 1997: Validation of the snow submodel of the Biosphere-Atmosphere Transfer Scheme with Russian snow cover and meteorological observational data. J. Climate, 10(2), 353-373.

Yen, Y., 1981: Review on thermal properties of snow, ice and sea ice. Spec. Rep. 81-10, U.S. Army Corps of Eng., Cold Reg. Res. and Eng. Lab, Hanover, N.H.

\section{Tables:}

Table 1: Current and original values for the coefficients for the amount distribution of precipitation in $\mathrm{SSiB}$.

\begin{tabular}{l|ccccc}
\hline Version of SSiB & $a_{c}$ & $b$ & $c_{c}$ & $a_{p}$ & $c_{p}$ \\
\hline New & 5.0 & 5.0 & $6.737946 \mathrm{e}-3$ & 0.0001 & 0.9999 \\
Original & 20.0 & 20.0 & $0.206 \mathrm{e}-8$ & 0.0001 & 0.9999 \\
\hline
\end{tabular}

Figures: 


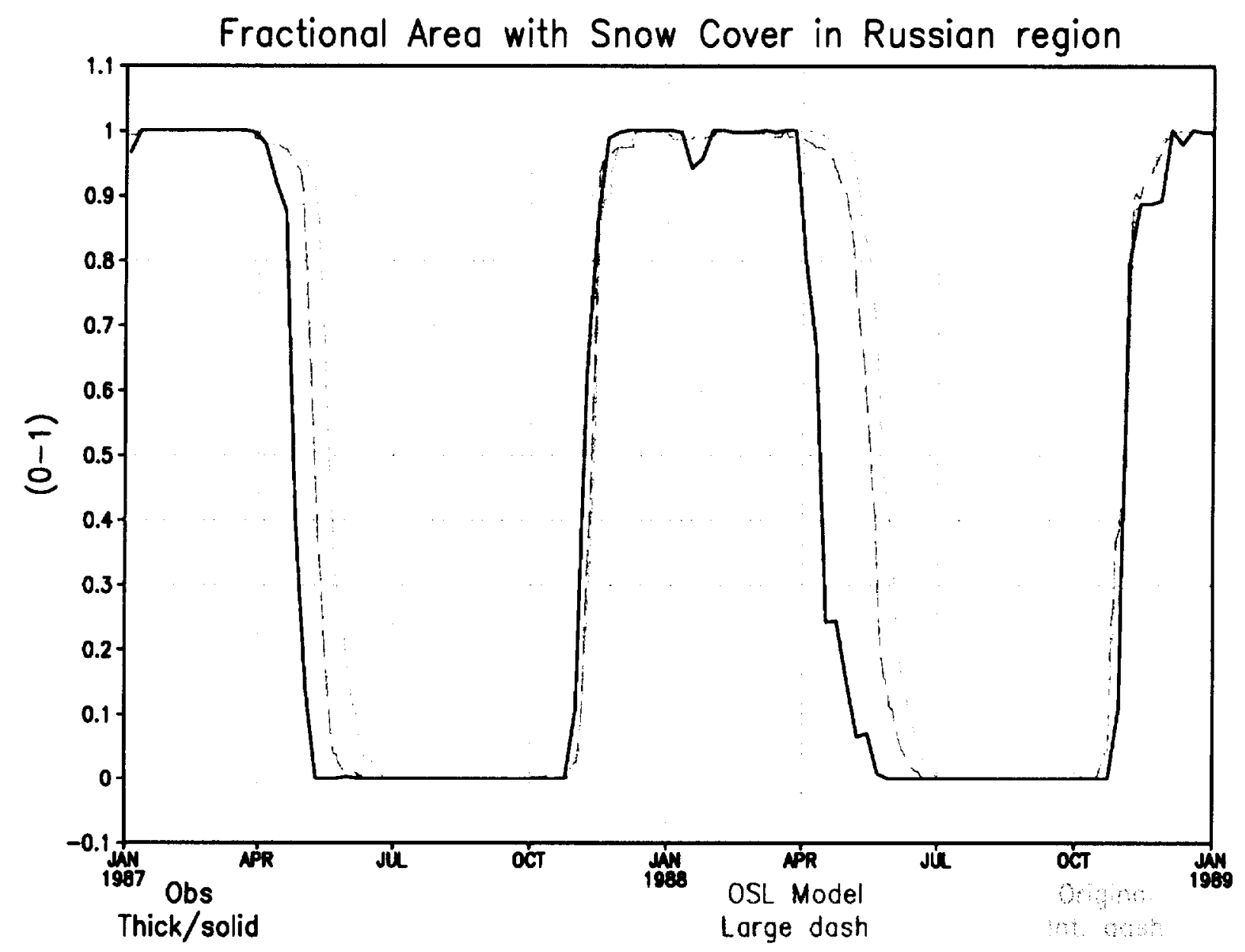

Figure 1: Line plot showing area-averaged snow cover fraction $\left(0^{-}-1\right)$ in the Russian Wheat Belt region for 1987-1988. The long dashed line is from OSL, while the intermittent dashed line is from original SSiB. The thick solid line is from observations taken from satellite. 


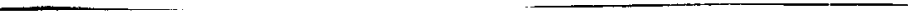




\section{OSL SSIB}

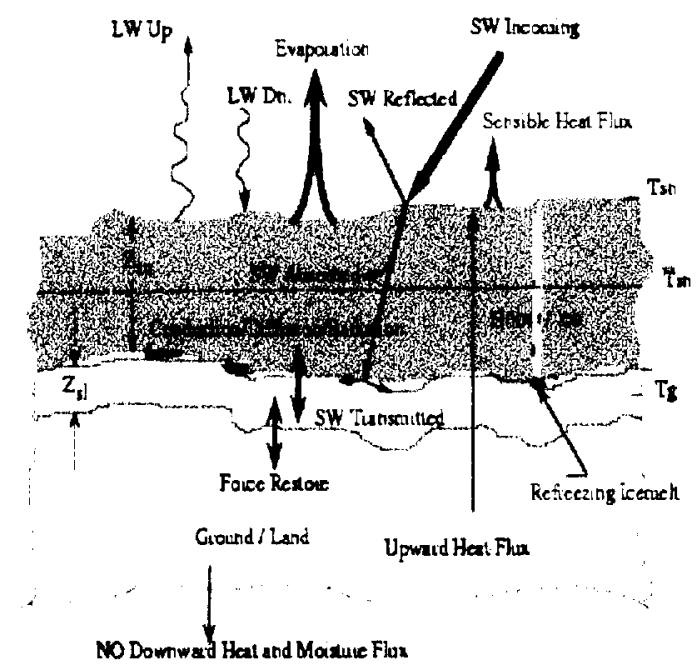

- Snow layer is separated from ground, with its own prognostic temperature and heat capacity

- Shortwave is partially absorbed by the snow or transunitited to ground

- Two ground layers as in original SSiB interant. through diurnal force-restore

- Heat transferred radiatively throngh thin air gap between ground and snow

- Snownelt can re-freeze and warm the ground

Reference:

Sud and Mocko, J.IS.J. 1999
TSL SSiB
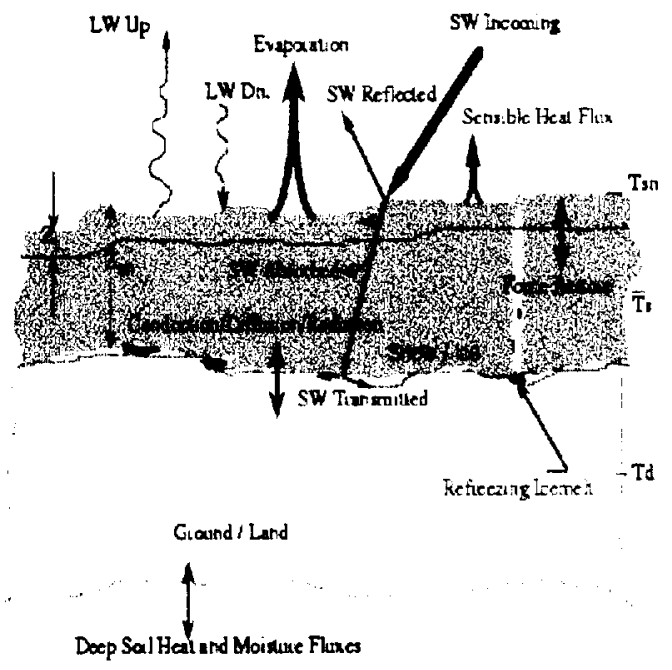

Further additions to OSL SSiB:

- Snowpack is divided into two layers - a diurnal layer atop a bulk layer

- Only one ground layer acts as an annual force-restore layer atop an infinite layer with fixed soil t.emperatiure

- Meltwater is further generated by diurual snow layer during warmer part of the day

Refereures:

Sud and Horko, AMS, CEWEX/GCTP, 1999

Figure 2: Schematics showing the major design features of two versions of the SSiB snow model. On the left is OSL and on the right is TSL. 



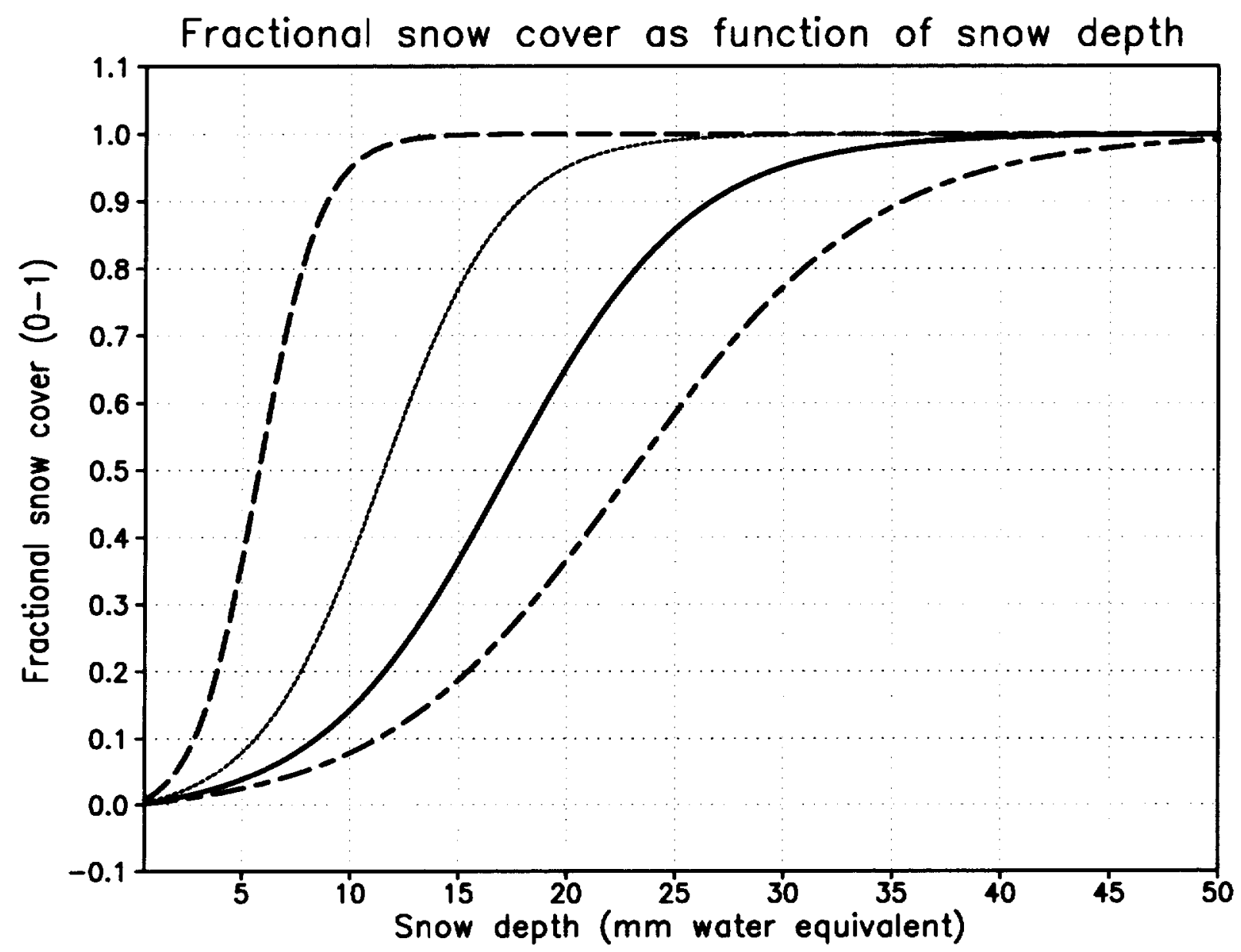

Figure 3: Fractional snow cover as a function of water equivalent snow depth for several representative snow densities: 1) long dash $-100 \mathrm{~kg} \mathrm{~m} \mathrm{~m}^{3}$, 2) short dash $-200 \mathrm{~kg} \mathrm{~m}^{3}$, 3) solid - $300 \mathrm{~kg} \mathrm{~m}$, and 4) intermittent dash - $400 \mathrm{~kg} \mathrm{~m}^{3}$. 



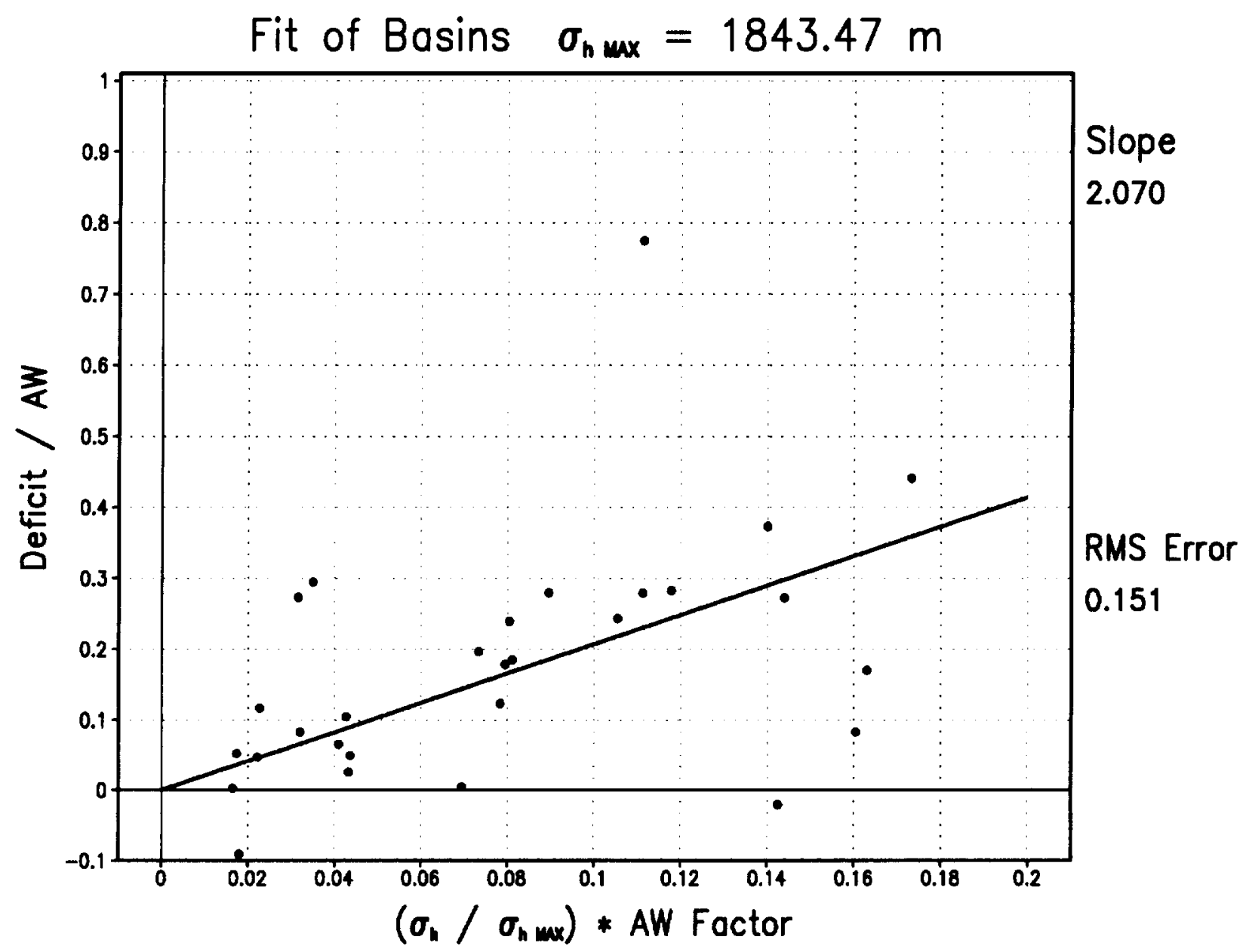

Figure 4: Scatter plot and least-squares approximation for annual runoff deficit values by standard deviation of orography for 29 basins around the globe for 1987-1988 data. 



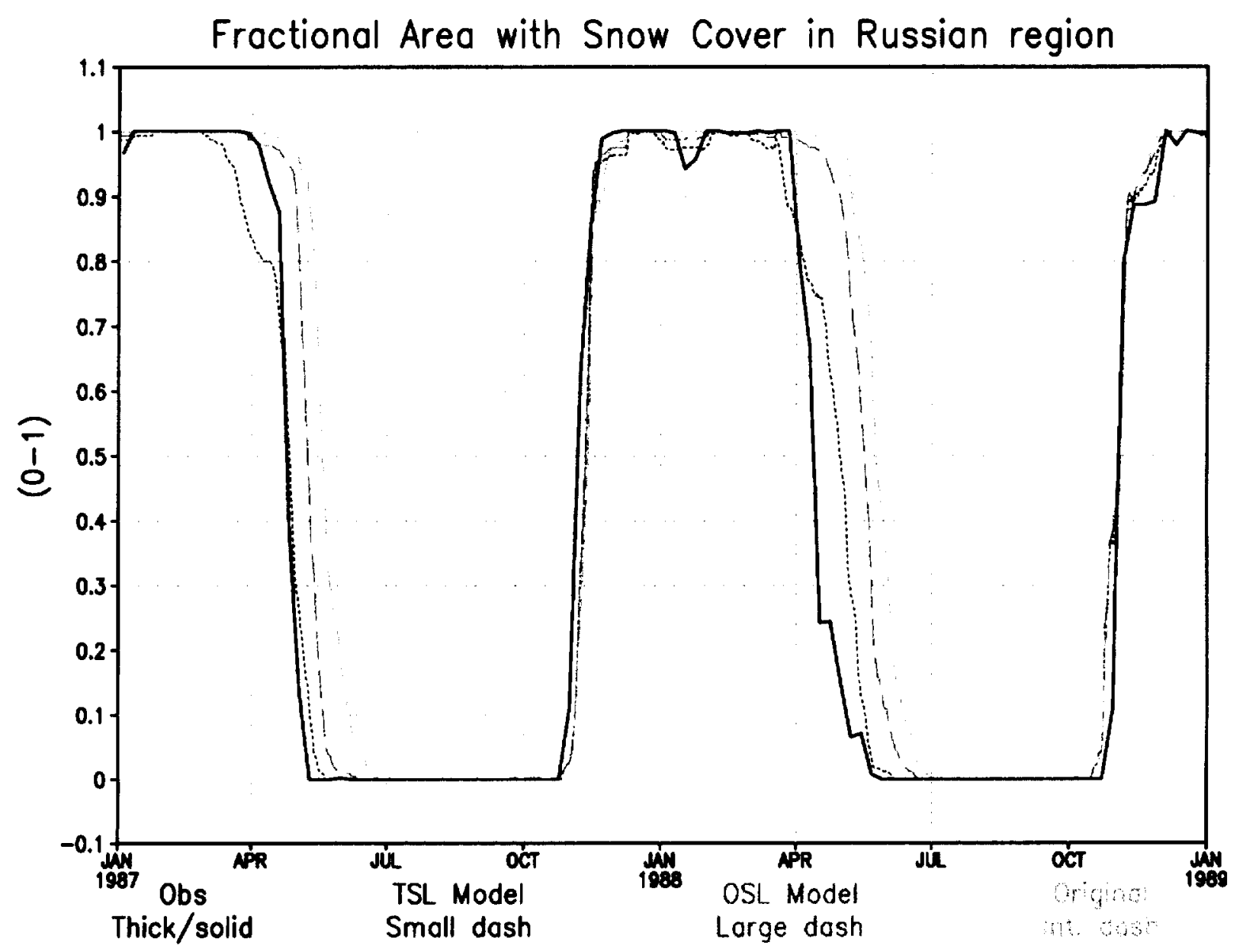

Figure 5: Line plot showing area-averaged snow cover fraction (0-1) in the Russian Wheat Belt region for 1987-1988, same as Figure 1, only with the addition of a short dashed line which is from TSL. 


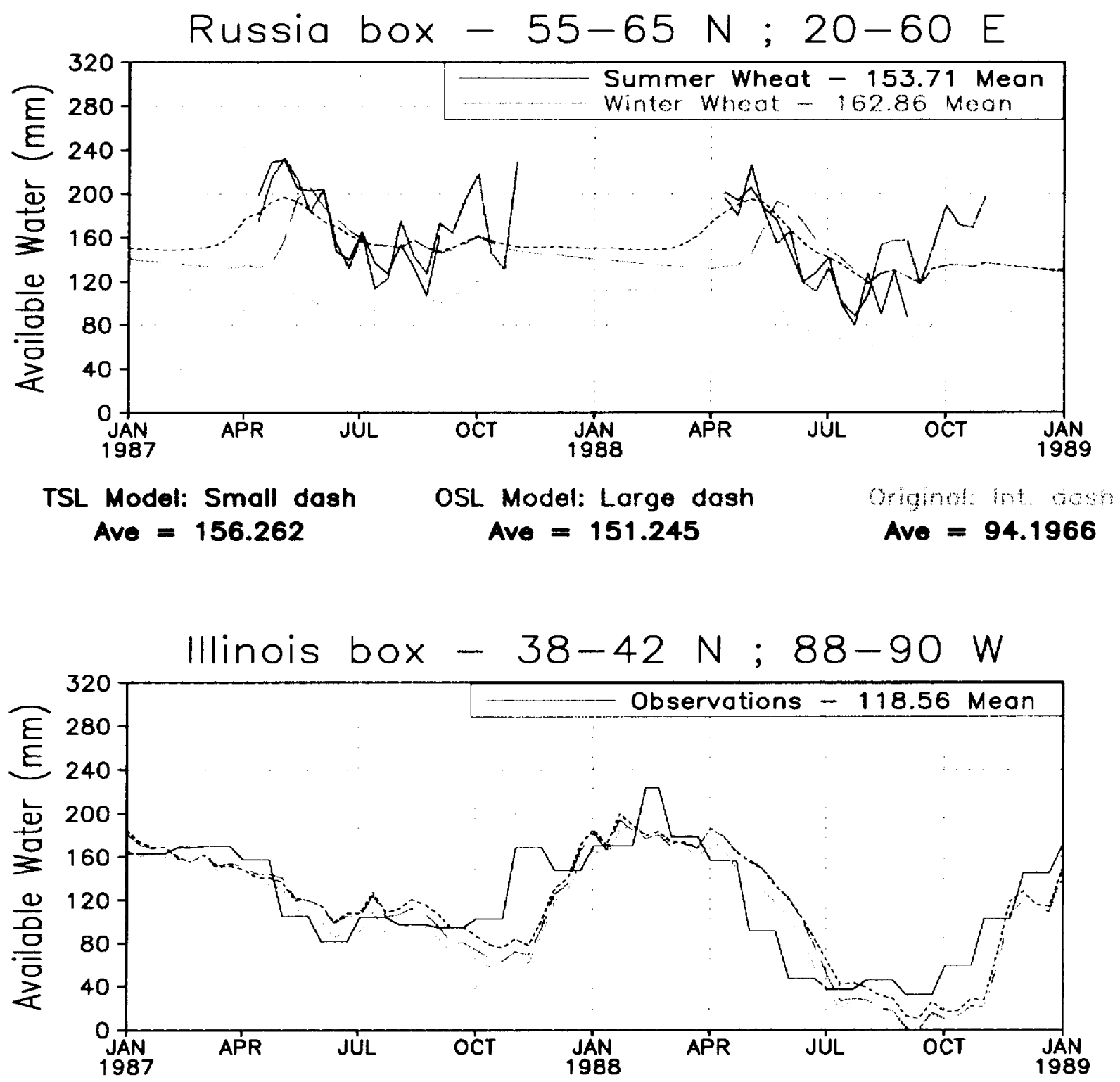

TSL Model: Small dash

Ave $=116.642$
OSL Model: Large dash

Ave $=111.843$

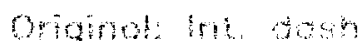

Ave $=104.145$

Figure 6: Time series of available water in $m m$ for (top) the Russia Wheat Belt region and (bottom) Illinois, United States for TSL, OSL, and original SSiB and observations (along with annual averages). 


-

- 


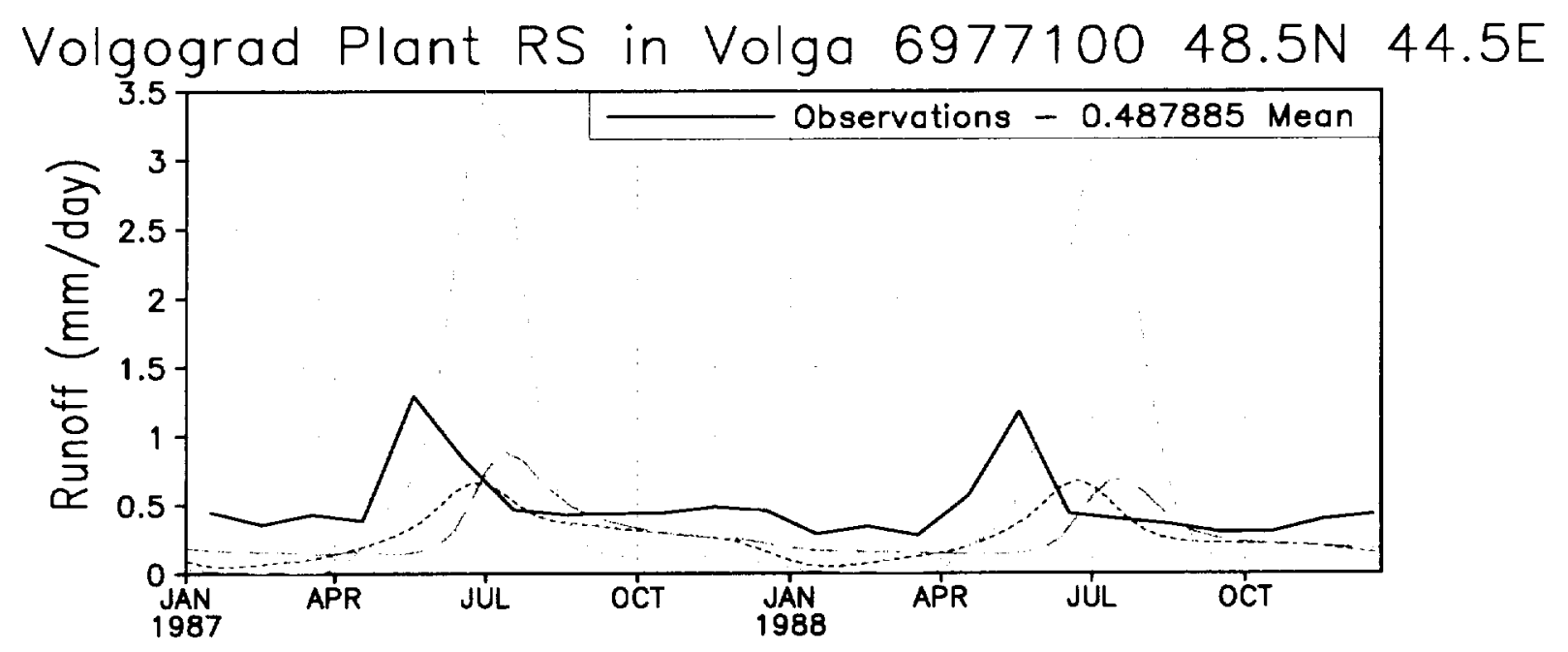

TSL Model: Small dash OSL Model: Large dash
Ave $=0.262054$
Ave $=0.283342$
Ave $=0.587457$

Vicksburg MS in Mississippi $412780032.5 \mathrm{~N} 91.5 \mathrm{~W}$

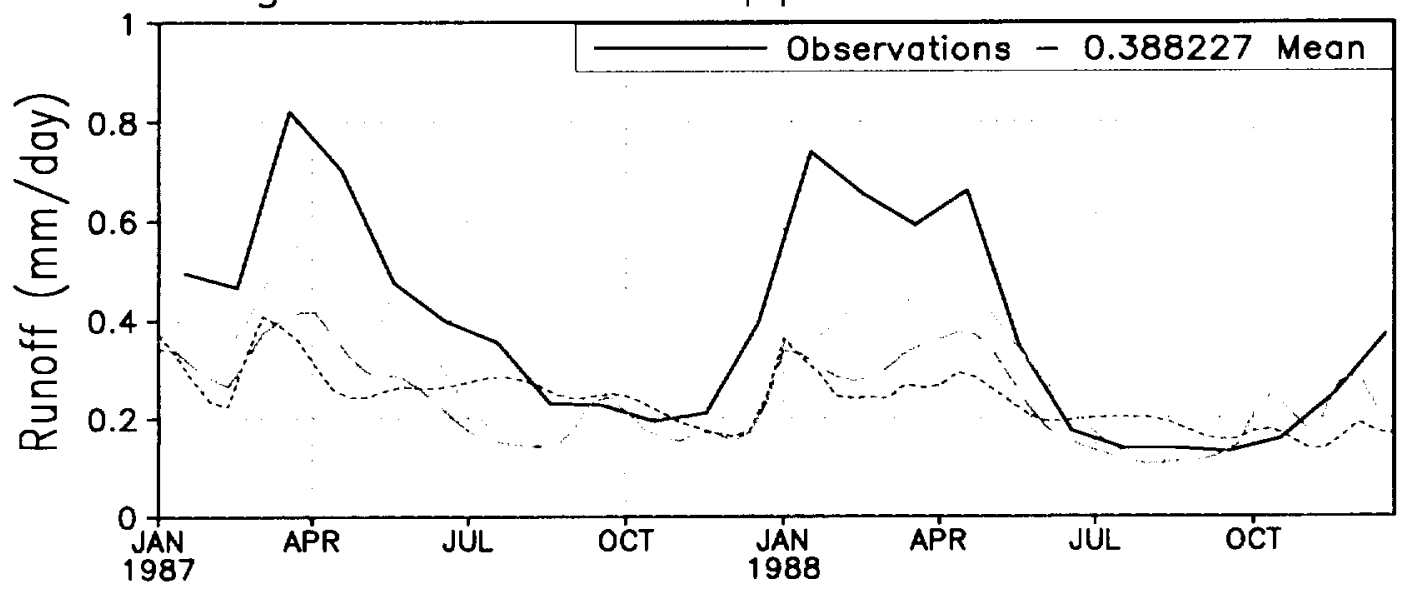

TSL Model: Small dosh OSL Model: Large dash Ave $=0.238453$

Figure 7: Time series of TRIP-routed stream flow in $m m d a y^{-1}$ for (top) the Volga River Basin in the Russia Wheat Belt region and (bottom) the Mississippi River Basin in the central United States for TSL, OSL, and original SSiB and observations from gauges (along with annual averages). Also shown are the basin size, the mean orography height, and the standard deviation of orography in the basin. 


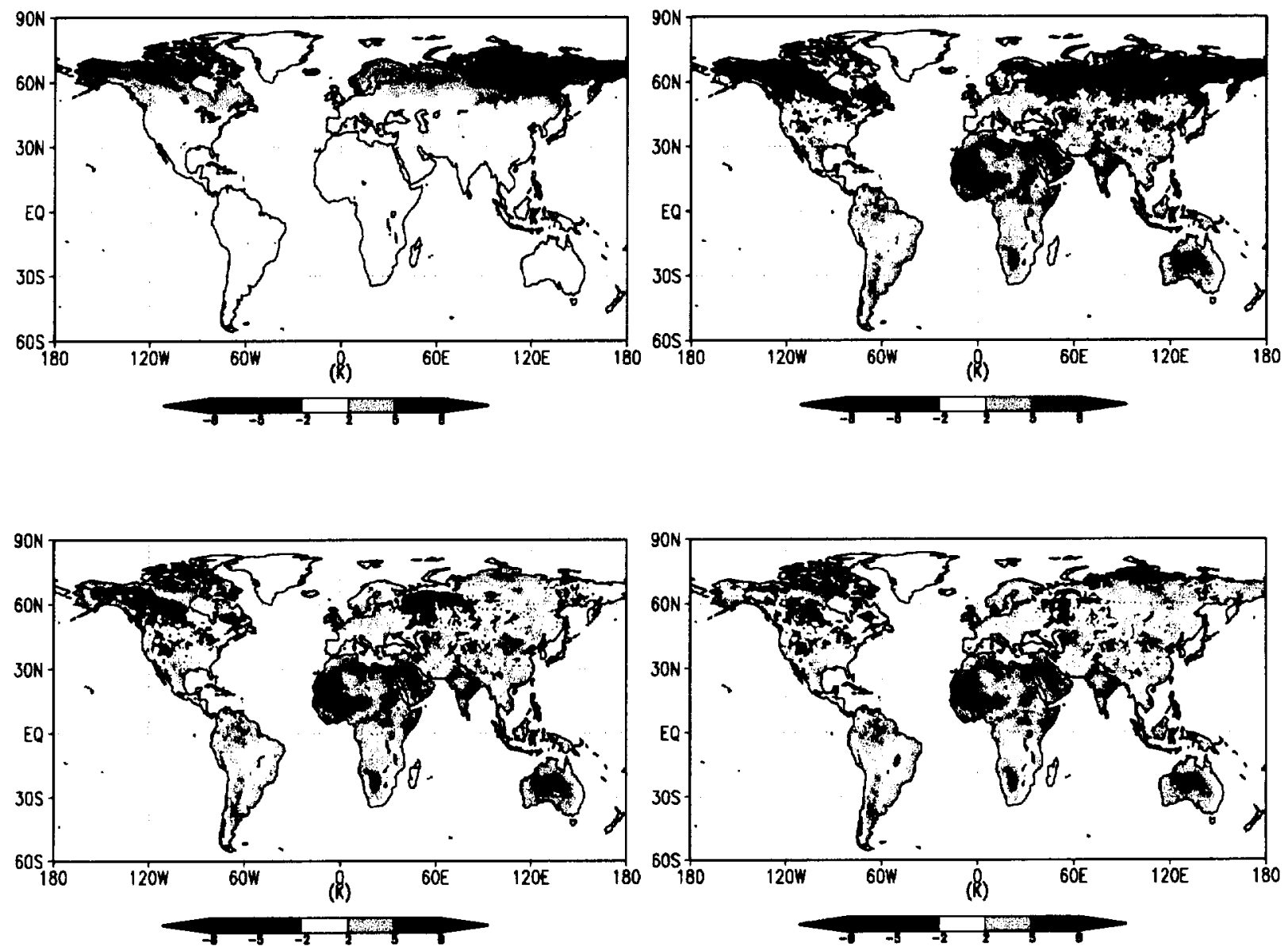

Figure 8: Four panels showing differences for May 1987 in global monthly averaged skin temperatures in $K$ between simulated and observations taken from satellite. The upper left panel is from TSL minus original SSiB, the upper right panel is original SSiB minus the satellite observations, the lower left panel is OSL minus the satellite observations, and the lower right panel is TSL minus the satellite observations. 



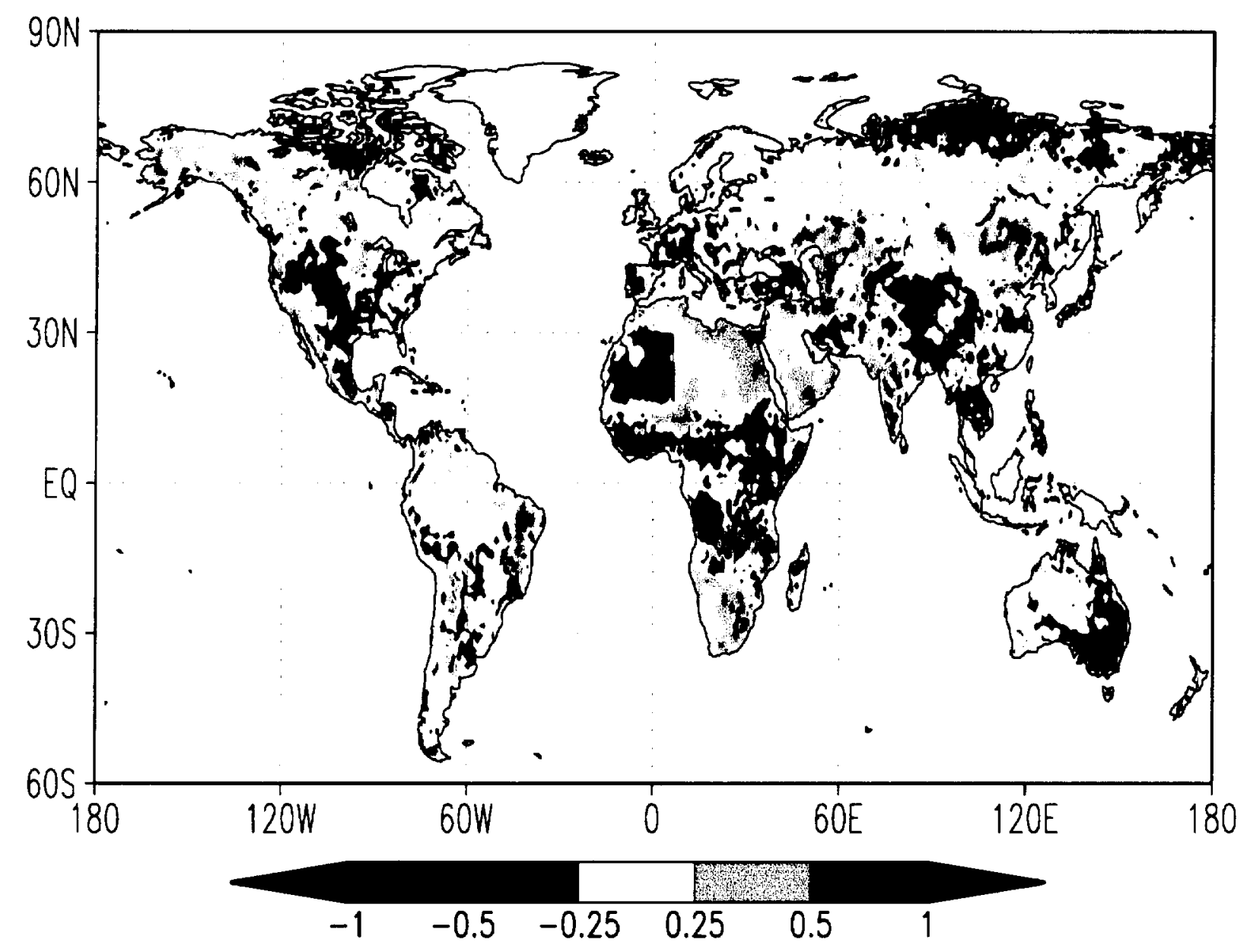

Figure 9: Global plot showing the difference between using and not using the buoyancy velocity scale in the TSL version of the model for May 1987 in the simulated skin temperatures in $K$. 



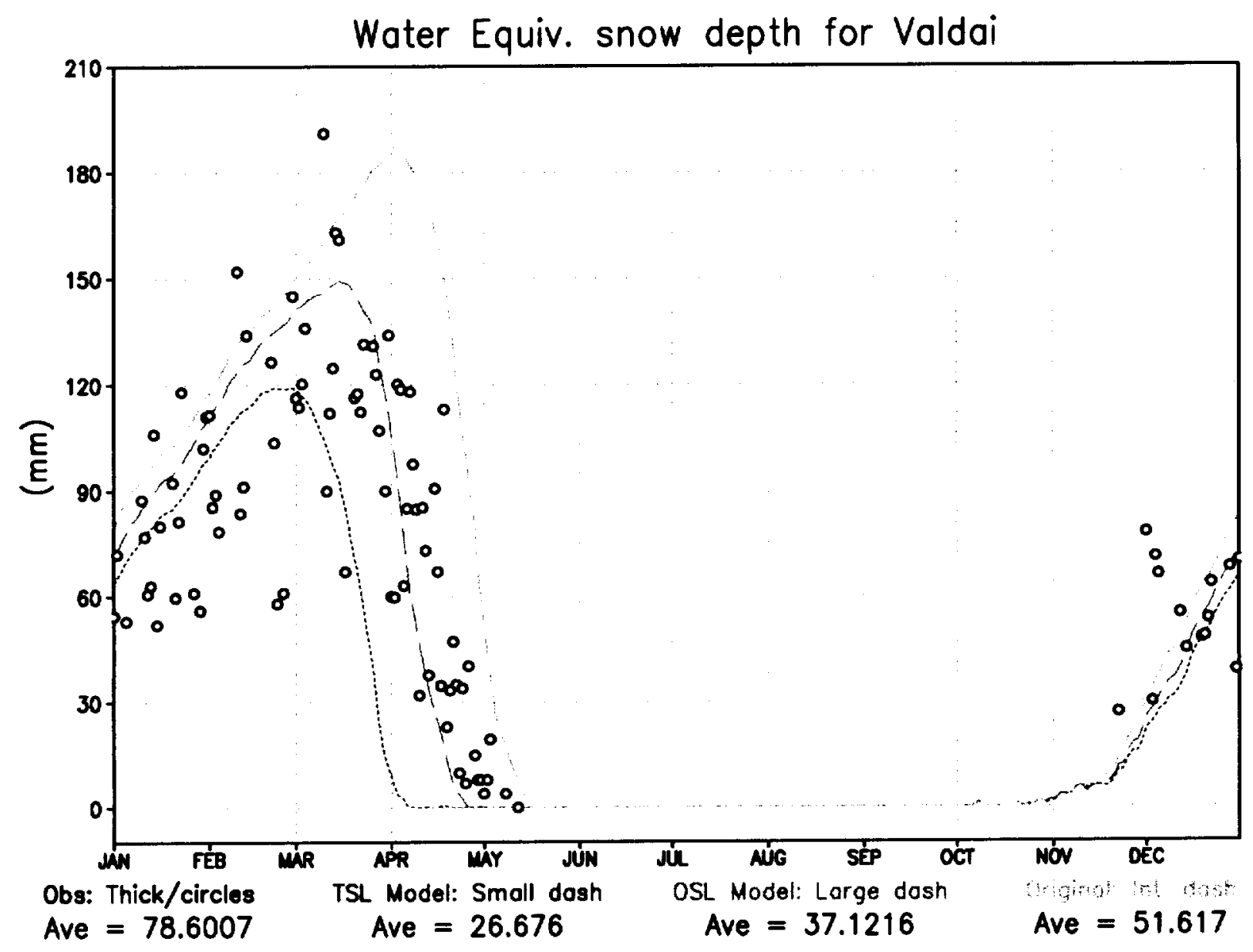

Figure 10: Annual averaged water equivalent snow depth in $\mathrm{mm}$ for the 18-year Valdai, Russia simulation. TSL is shown with a small dash, OSL is shown with a large dash, and original SSiB is shown with a variable dash. The observations are shown as circles plotted at the time of year of the measurement. 


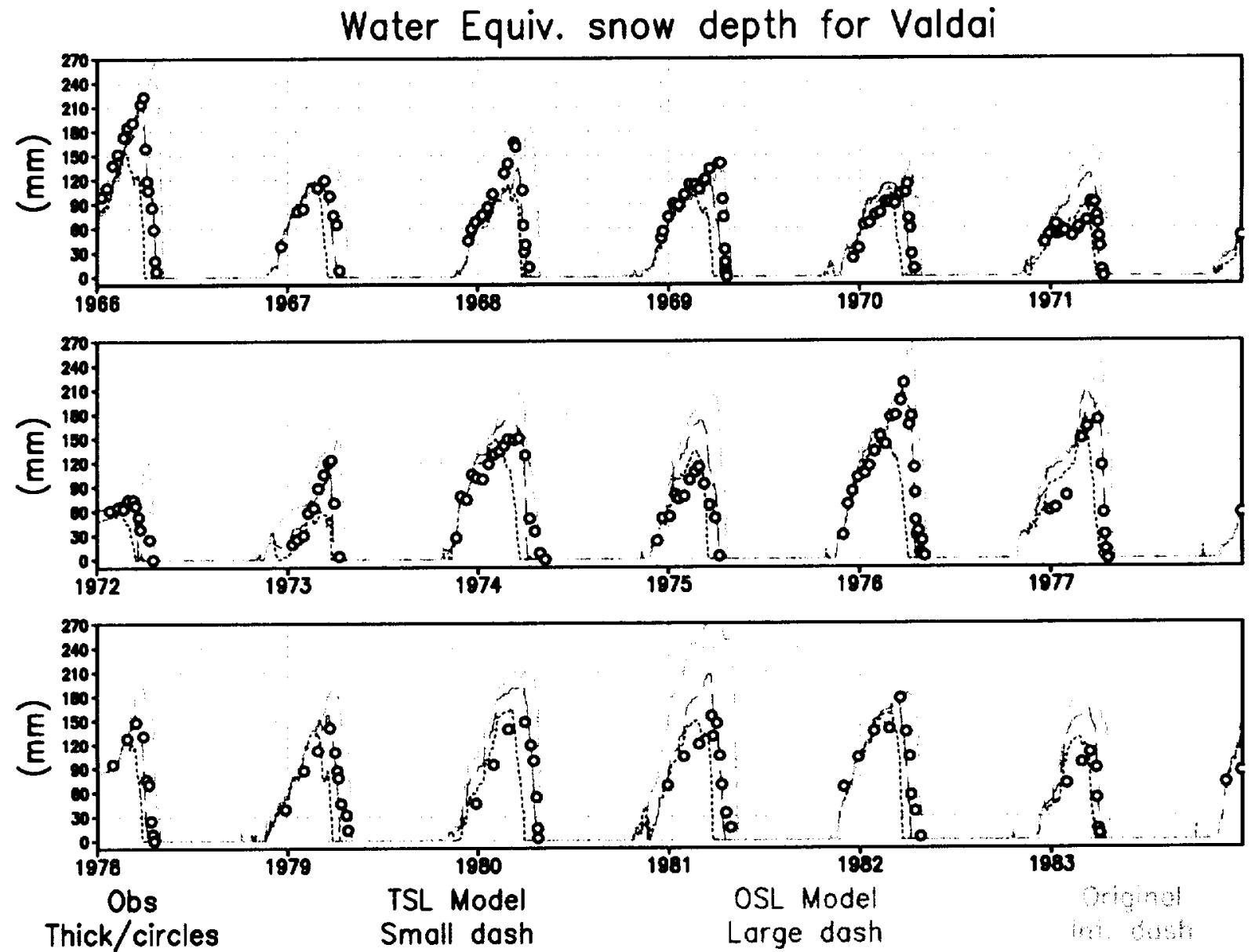

Figure 11: Same as Figure 10, only now showing an 18-year time series of the water equivalent snow depth in $m m$. 



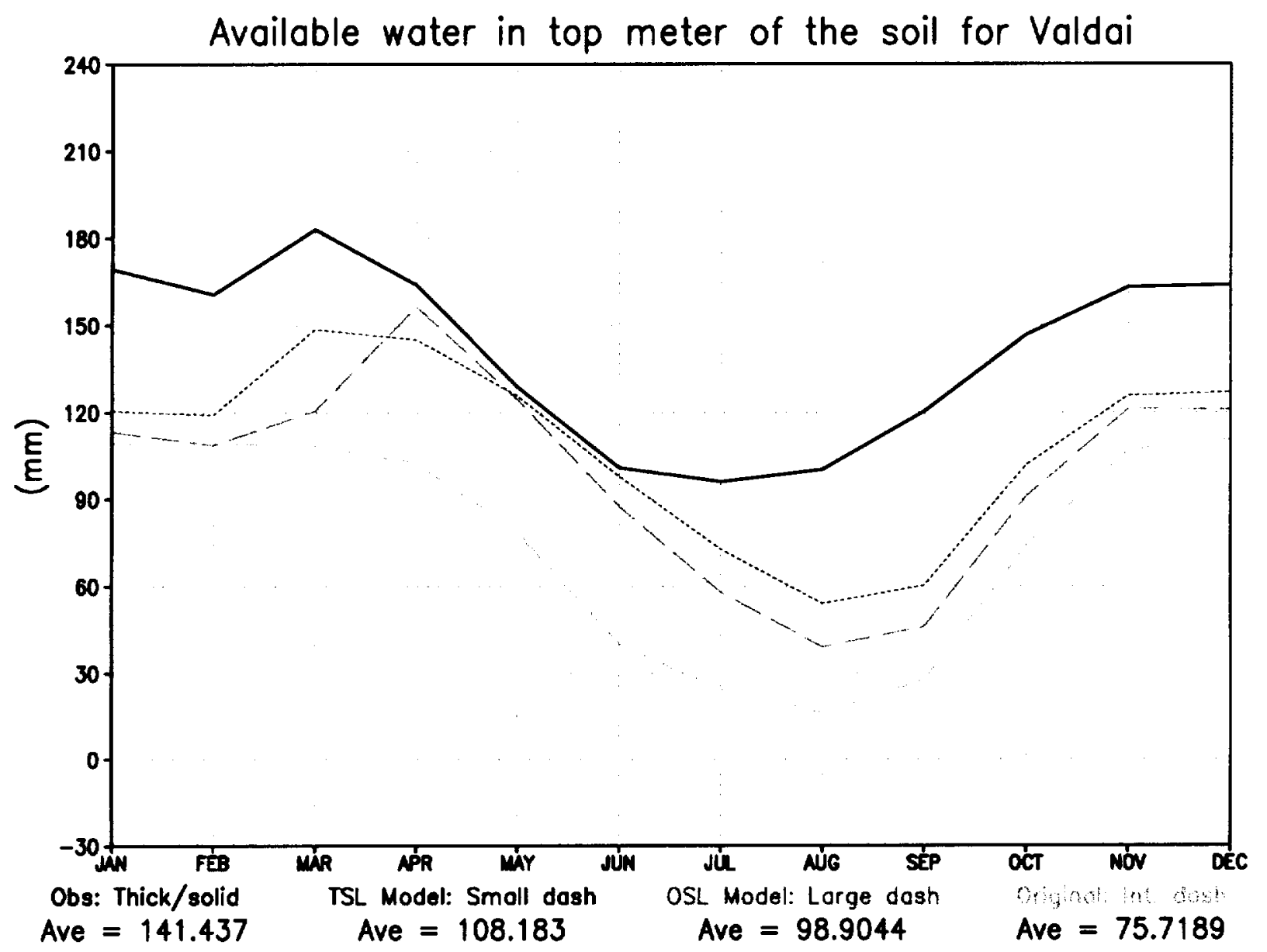

Figure 12: Same as Figure 10, only for the annual averaged soil moisture in $\mathrm{mm}$ in the top meter of the soil. The observed values are shown with a thick solid line. 


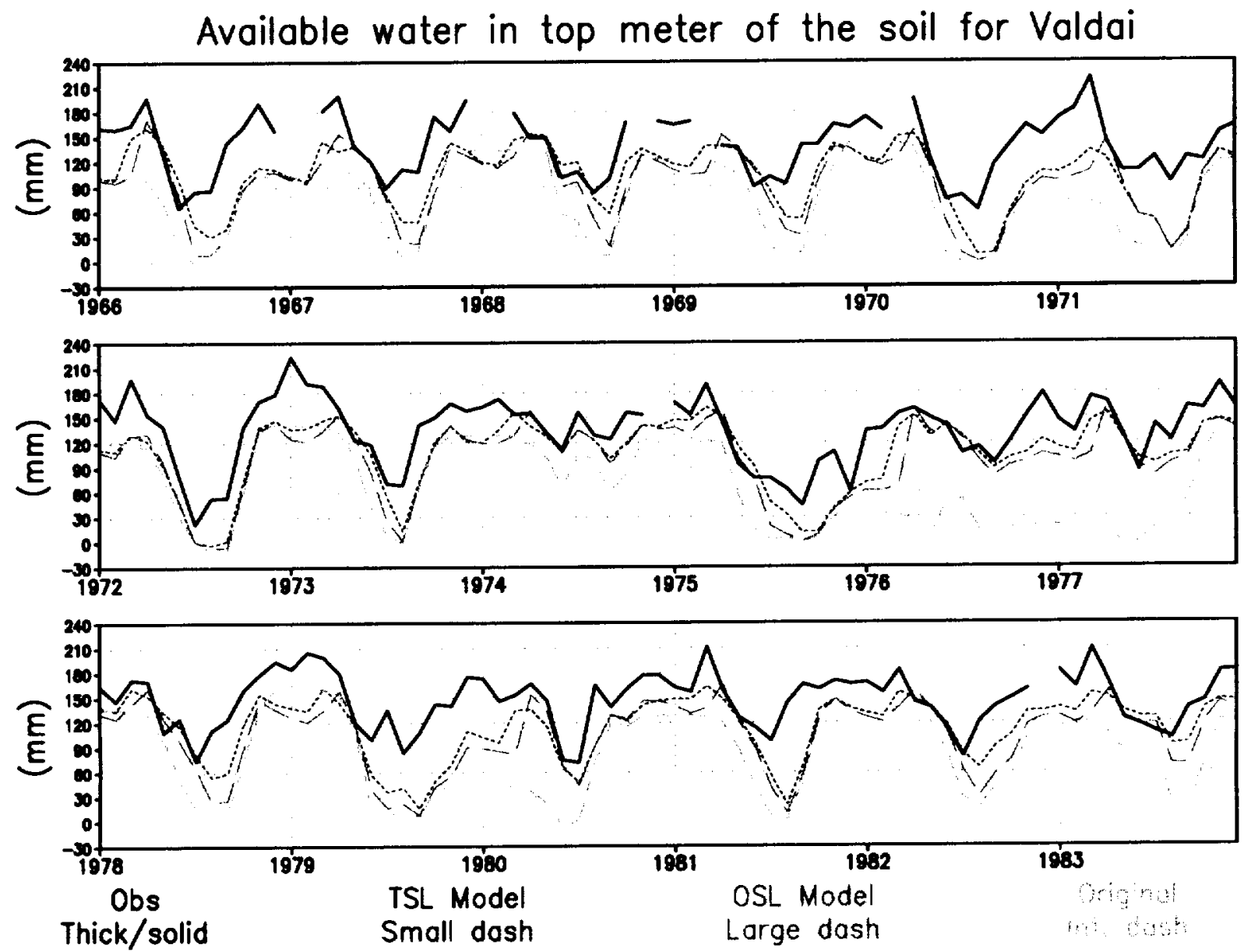

Figure 13: Same as Figure 12, only now showing an 18-year time series of the soil moisture in $m m$ in the top meter of the soil. 



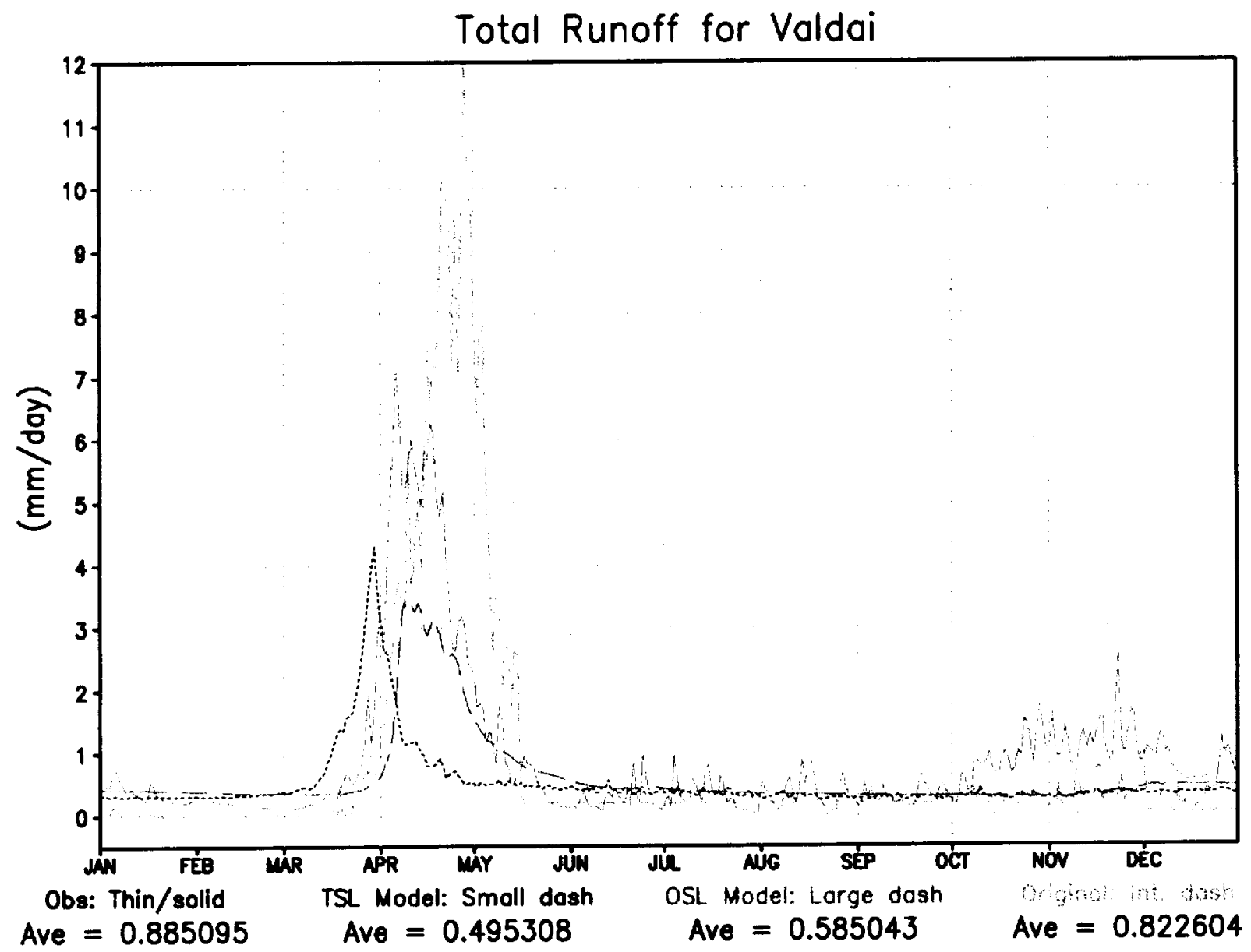

Figure 14: Same as Figure 12, only for the total runoff in $m m d a y^{-1}$. The observed values are shown with a thin solid line. 



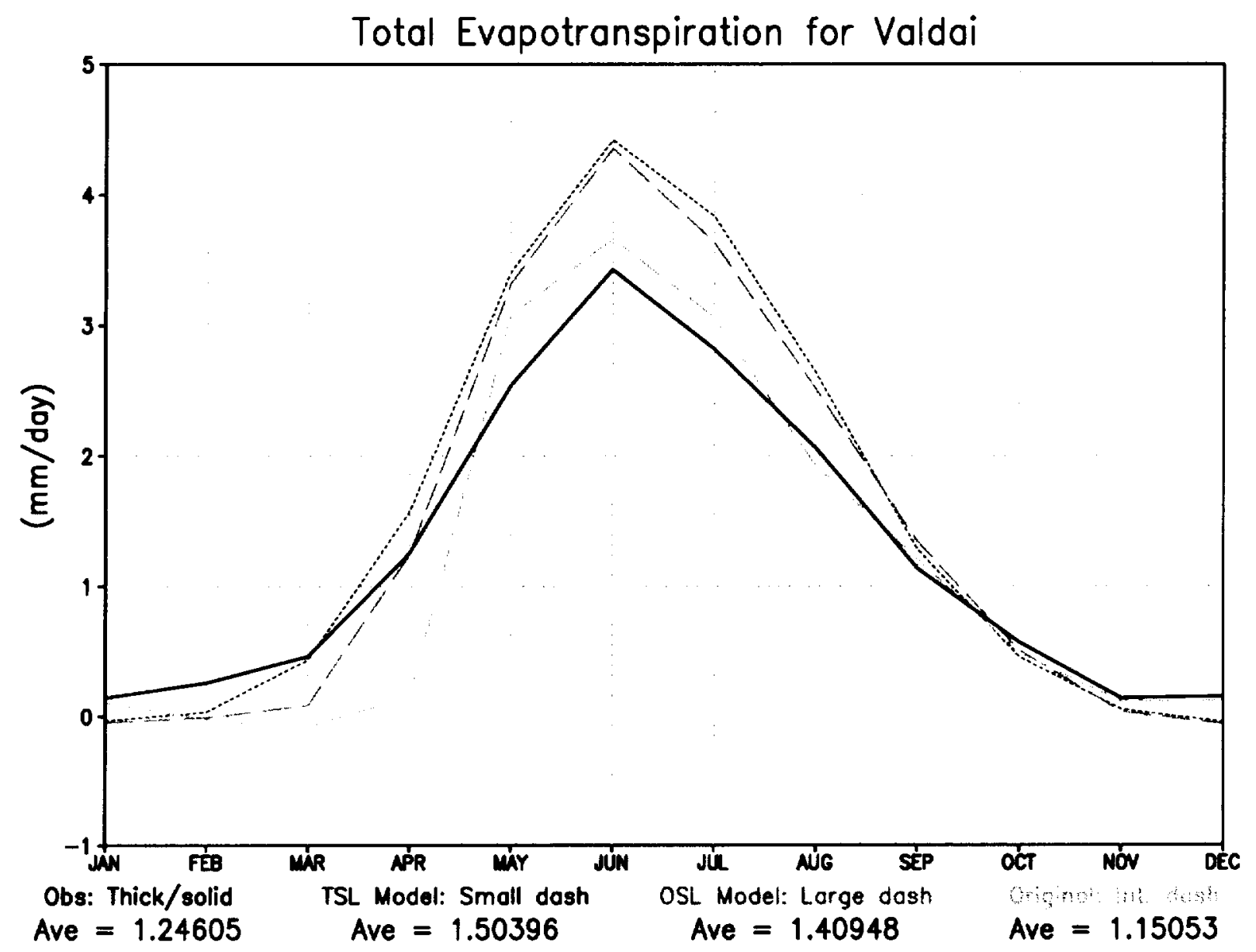

Figure 15: Same as Figure 12, only for the total evapotranspiration in $m m d a y^{-1}$. 



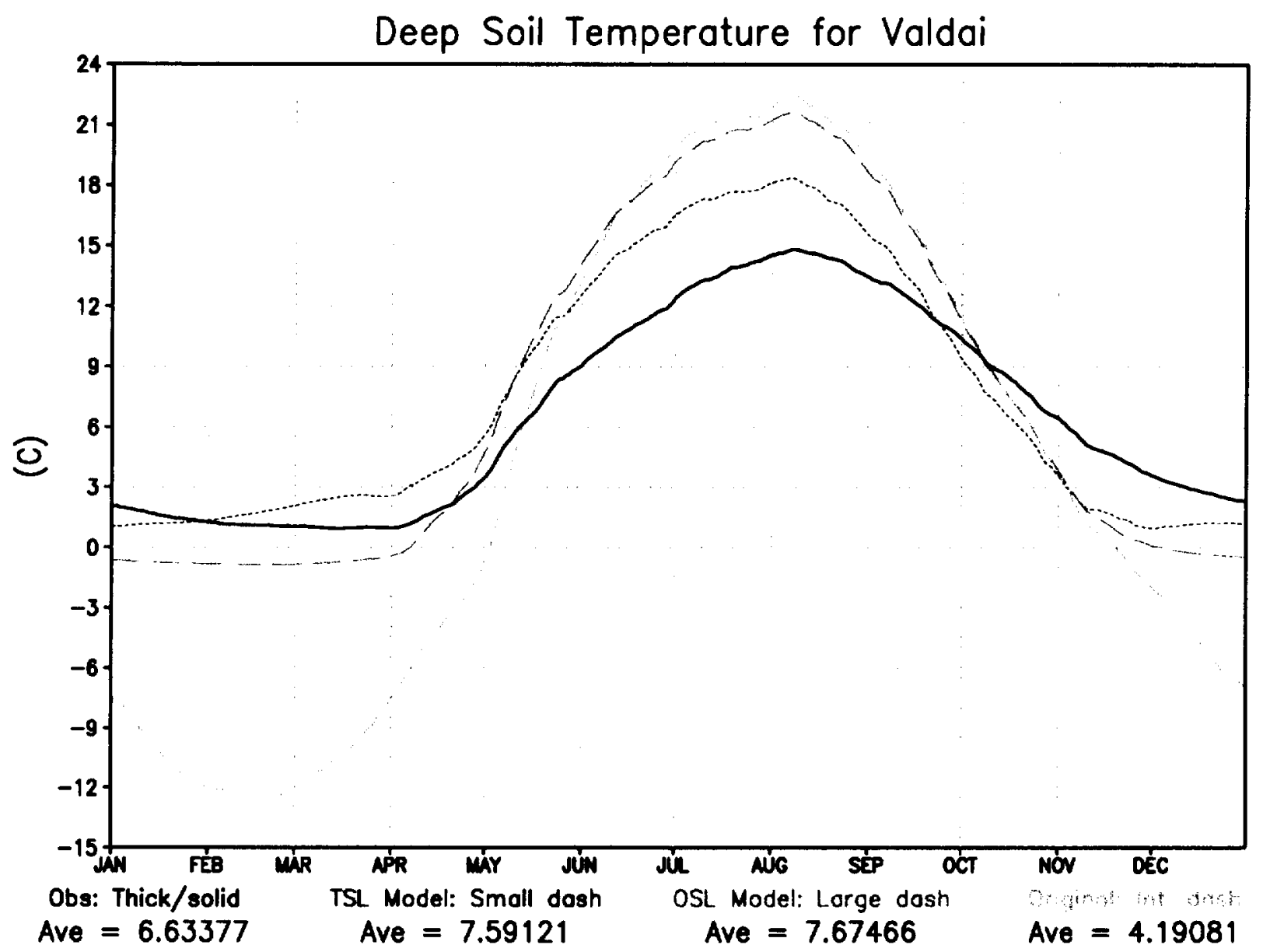

Figure 16: Same as Figure 12, only for the deep soil temperature in $C$. 
